\title{
Impacts of climate change on the complex life cycles of fish
}

\author{
Pierre Petitgas ${ }^{1, *}$, Adriaan D. Rijnsdorp ${ }^{2}$, Mark Dickey-Collas ${ }^{2, a}$, Georg H. Engelhard ${ }^{3}$, Myron A. Peck ${ }^{4}$, \\ John K. Pinnegar ${ }^{3}$, Ken Drinkwater ${ }^{5}$, Martin Huret ${ }^{1}$, Richard D. M. Nash ${ }^{5}$ \\ ${ }^{1}$ IFREMER, Plouzané, France \\ 2 IMARES, IJmuiden, The Netherlands \\ ${ }^{3}$ CEFAS, Lowestoft, Suffolk, UK \\ ${ }^{4}$ IHF, University of Hamburg, Hamburg, Germany \\ ${ }^{5}$ IMR, Nordnes, Bergen, Norway \\ ${ }^{a}$ Present address : ICES, Copenhagen V, Denmark \\ *: Corresponding author : Pierre Petitgas, email address : pierre.petitgas@ifremer.fr
}

\begin{abstract}
:
To anticipate the response of fish populations to climate change, we developed a framework that integrates requirements in all life stages to assess impacts across the entire life cycle. The framework was applied on plaice (Pleuronectes platessa) and Atlantic herring (Clupea harengus) in the North Sea, Atlantic cod (Gadus morhua) in the Norwegian/Barents Seas and European anchovy (Engraulis encrasicolus) in the Bay of Biscay. In each case study, we reviewed habitats required by each life stage, habitat availability, and connectivity between habitats. We then explored how these could be altered by climate change. We documented environmental processes impacting habitat availability and connectivity, providing an integrated view at the population level and in a spatial context of potential climate impacts. A key result was that climate-driven changes in larval dispersion seem to be the major unknown. Our summary suggested that species with specific habitat requirements for spawning (herring) or nursery grounds (plaice) display bottlenecks in their life cycle. Among the species examined, anchovy could cope best with environmental variability. Plaice was considered to be least resilient to climate-driven changes due to its strict connectivity between spawning and nursery grounds. For plaice in the North Sea, habitat availability was expected to reduce with climate change. For North Sea herring, Norwegian cod and Biscay anchovy, climate-driven changes were expected to have contrasting impacts depending on the life stage. Our review highlights the need to integrate physiological and behavioural processes across the life cycle to project the response of specific populations to climate change.
\end{abstract}

Keywords : anchovy ; Cod ; Connectivity ; eco-physiology ; habitat ; herring ; plaice 
The effect of a changing climate on fish resources has been documented at different levels of biological organization (Pörtner and Peck, 2010), from individual physiological and behavioural responses to effects at the population level (Rijnsdorp et al., 2009), to changing species proportions in fish assemblages (Engelhard et al., 2011a) and to ecosystem re-organization (Beaugrand, 2004). Yet, the impact of climate change on the links in the life cycle has received little attention, especially considering that they could represent additional mechanisms and vulnerabilities of relevance to physiological tolerance envelopes that might explain observed changes in the spatial distribution of species. For instance, when predicting changes in the distribution of species using bioclimate envelopes (e.g., Cheung et al., 2008) the life cycle is greatly simplified as the requirements of the different life history stages are rarely considered nor are the connectivity pathways between their habitats. Here we develop a generic life cycle framework to analyse how climate variability and change may impact marine fish populations.

Fish have complex life cycles that comprise different stages exploiting a variety of habitats (Rijnsdorp et al., 2009). For life cycle closure, larval dispersal and fish movements are often necessary to connect spatially-separated habitats utilized by successive life stages (Harden-Jones, 1968; Sinclair, 1988). Each life stage has particular habitat requirements that are based, in part, on stage-specific physiological requirements. The availability of habitats with the required abiotic and biotic characteristics will undoubtedly change both spatially and temporally as a result of short-term (weeks to years) environmental variability and longer-term (years to decades) climate variability and change. Thus, it is critical to characterize the life cycle of species in terms of specific habitat requirements, habitat availability, and connectivity.

To illustrate changes in habitat availability and connectivity occurring at the species-level, the migration triangle originally depicting life cycle closure (e.g., HardenJones, 1968) was redrawn in a climate change context (Fig. 1), which shows the need to integrate climate impacts occurring during all life stages. To explore the usefulness of this life cycle approach in assessing the potential effects of climate change on fish populations, we study the habitat requirements of successive life history stages in relation to the availability of suitable habitats and the connectivity between them. 
and can thus be considered to be critical to understanding climate impacts on populations.

As such, this study provides an integrated approach to assess the aggregate population level response to potential climate impacts on selected, commercially important marine fish species in European waters.

\section{ANALYSIS FRAMEWORK AND SPECIES CONSIDERED}

To achieve some generality in the analyses, case study species and populations were chosen to represent a range of life history types (Table 1) and which are known to occupy habitats possessing varying degrees of complexity over a latitudinal range of ecosystems. Species/stocks chosen were 1) European anchovy Engraulis encrasicolus in the Bay of Biscay, 2) Atlantic herring Clupea harengus in the North Sea, 3) European plaice Pleuronectes platessa in the North Sea, and 4) Atlantic cod Gadus morhua in the Norwegian/Barents Seas (Northeast Arctic cod). Habitat requirements were considered at the species level while habitat availability and connectivity were considered at the population level within particular regions. Based on literature reviews, qualitative categorizations were argued for each life stage, including eggs, larvae, juveniles, feeding and spawning adults (Tables 2 to 5). Where appropriate, sub-stages were considered, e.g., pelagic larvae / juveniles versus demersal juveniles.

Each case study was reviewed using a similar template. For each life stage, (i) physiological habitat requirements, (ii) habitat availability, and (iii) connectivity to the next life stage were examined, followed by (iv) an assessment of the likely impact of climate variability and climate change on each of these factors. Habitat requirements were defined by physiological requirements, critical habitat features such as specific topographic or sediment features, or other requirements that were based on first principles. Habitat requirements were ranked qualitatively in terms of importance within categories of "narrow" (restrictive), "medium" or "broad" (less restrictive). Habitat availability considered how accessible the required conditions were to the species in the studied region, i.e., the geographical location of habitats, vertical distribution, timing in the season, etc. Habitat availability was summarized with a glossary made of three terms: "ok" (no significant problem of availability expected), "small" (reduced availability), or "var" (high inter-annual variability). Connectivity considered how the habitat of one life stage was linked to that of the next life stage, such as through drift and dispersal (e.g. egg to larval phase) including the importance of behaviour (e.g. 
113 vertical movements) and 'active' migration (e.g. feeding to spawning adults).

114 Connectivity was summarized within each of the studied regions using the following 115 terms: "ok" (little sensitive to environmental variability: connectivity assured), "crucial" 116 (precise connectivity needed for life cycle closure), and "var" (high inter-annual 117 variability). To evaluate the potential impact of climate change on life cycles, we 118 focussed the analyses of impacts on the availability of suitable habitats for the different

119 life stages and on the connectivity between habitats and life stages. Again, a qualitative 120 categorisation was used to characterize the expected impacts. The following categories were used: "larger" or "smaller" (spatio-temporal extension or contraction of suitable habitats), "shift" (spatio-temporal displacement of suitable habitats), "ok" (no particular impact expected) and “?” (unknown consequences).

124 The categorizations were based on a critical review of the literature for each 125 species and populations and compiled in Tables 2 to 5. The following sections justify 126 the categorization presented in these tables.

\section{European anchovy}

\section{European anchovy: habitat requirements}

130 European anchovy is a fecund, indeterminate multiple batch spawner. The start of

131 the spawning season coincides with the initiation of seasonal stratification and a 132 concomitant increase in surface water temperature above $14{ }^{\circ} \mathrm{C}$ occurring in April or 133 May and eggs are generally found in the surface layer $(<15 \mathrm{~m})$ (Motos et al., 1996; 134 Planque et al., 2007). Adult European anchovy shows a versatile feeding ecology 135 (Tudela and Palomera, 1997; Plounevez and Champalbert, 1999; Raab et al., 2011). The 136 species feeds mainly on medium-sized copepods (0.5 to $1.5 \mathrm{~mm})$ and cladocereans but 137 also ingests mysids and phytoplankton. The average daily ration of adults during 138 spawning is $\sim 20 \%$ wet body weight (Bulgakova, 1992). The consumption rates of 139 zooplankton by anchovy in the western Mediterranean Sea can represent $20 \%$ of the 140 mesozooplankton spring production (Tudela and Palomera, 1997). Despite this, no food 141 limitation has been reported during this period (Marquis et al., 2006). Feeding continues 142 during spawning allowing fish to extend the spawning season in years when prey 143 resources are abundant (Dubreuil and Petitgas, 2009). Therefore the requirements for 144 spawning adults seem moderately restrictive, the major constraints being that minimum 145 temperature thresholds are reached and that spawning is initiated during the onset of 146 zooplankton production. 
The larvae are found during the summer within stratified waters (Allain et al., 2007; Irigoien et al., 2008) and growth is potentially most rapid above $16{ }^{\circ} \mathrm{C}$

149 (Urtizberea et al., 2008). The larval stage lasts approximately 1 to 2 months (La Mesa,

150 2009; Aldonando et al., 2010). The larvae feed on microzooplankton and 151 mesozooplankton in the size range 50 to $500 \mu \mathrm{m}$ (Tudela et al., 2002) with prey size 152 increasing with increasing larval size. Although the nutritional condition of larvae has 153 been related to carbohydrate assimilated from feeding on mesozooplankton (Bergeron, 2009), food-limited growth has not been reported during the larval stage (Diaz et al., 2008). However the vertical structure of larval habitats has been correlated with larval condition and ultimately recruitment. Detrimental conditions include frequent gales (Bergeron, 2004) as well as intense stratification (Allain et al., 2007).

Early juveniles are found in late summer and autumn in stratified waters that are > $18^{\circ} \mathrm{C}$. Depending on the direction and intensity of currents as well as dispersion, larvae can be transported into many different areas, from near-shore coastal habitats to offshelf oceanic areas (e.g., Petitgas et al., 2010a). There is a lack of information on juvenile habitat requirements, but these seem to be broad, as suggested by the distribution of juveniles in a variety of habitats. However, in the Bay of Biscay a minimum length (ICES, 2009) and/or energy content (Dubreuil and Petitgas, 2009) appear necessary for juveniles to survive the overwinter period. This could also be a limiting factor in the southern North Sea as increased winter temperatures are associated with increased survival through to age 1 (Kanstinger and Peck, 2009; Petitgas et al, 2012)

Overall, habitat requirements of larvae are satisfied via a temporal match between seasonal warming, river plumes, and zooplankton production and were thus considered medium. Juveniles are widely distributed and their habitat requirements were classified as broad (Table 2, column 1).

\section{European anchovy: habitat availability in the Bay of Biscay}

Pelagic habitats within the Bay of Biscay are dynamic and characterized by the presence of a variety of meso-scale physical features such as river plumes, upwelling areas, gyres, eddies and fronts with the strength of these features depending upon the season and climatic conditions (Koutsikopoulos and Le Cann, 1996). The anchovy life cycle in the Bay of Biscay is associated with seasonal changes in a variety of these physical features and to specific biological factors. For example, water temperature is 
181 one of the triggers for spawning and interannual differences in water temperature may

182 lead to interannual differences in spawning times. Moreover, clear limits to habitat availability for spawning exist in the northern Bay of Biscay, where water temperatures are often too cold and unsuitable for spawning until late spring. The spawning duration may vary between years depending upon the feeding conditions encountered on spawning grounds. In spring, the zooplankton production seems sufficient as no feeding limitation has been reported (Marquis et al., 2006). In summer, warmer temperatures associated with lower plankton production can be unsuitable for the adults in the southern Biscay (Struski et al., 2009). Larval drift can vary significantly among years depending on wind conditions and river discharges (Allain et al., 2007; Huret et al., 2010), with consequences for survival and ultimately recruitment. Specifically, prey fields may vary with hydrographic conditions and higher predation is thought to occur within on-shelf areas as opposed to off-shelf areas (Irigoien et al., 2007).Autumn and winter temperature and feeding conditions also affect reserve storage and juvenile growth with consequences for the energy available for spawning in the subsequent spring (Pecquerie et al., 2009). Thus, the habitat requirements of anchovy in the Bay of Biscay in the different life stages seem to be satisfied in many but not all years, as evidenced by the recruitment variability observed in the region. Therefore, we considered habitat availability as not limiting although variable from year to year (Table 2, column 2).

European anchovy: habitat connectivity in the Bay of Biscay

Connectivity between habitats for the Bay of Biscay anchovy population was summarized in Petitgas et al. (2010a). The spring spawning habitats are mainly located in the southern regions of the Bay Biscay, associated with river plumes, as well as offshore close to the shelf-break (Motos et al., 1996). From these locations, larval drift is generally oriented along shelf to the southwest although large cross-shelf dispersion can also occur. Late larvae and early juvenile habitats are widely distributed, covering the shelf and off-shelf areas (Irigoien et al., 2008; Petitgas et al., 2010a), but they appear to

210 be mostly confined to the south of the bay. Off-shore juveniles actively migrate back to

211 the coastal areas. The mechanism controlling this migration is unknown. When they

212 encounter adults and recruit to the population in autumn, juveniles change their 213 schooling behaviour (Petitgas, 2007). Adults seem, therefore, to play the role of 214 facilitators, enhancing naive juveniles to rapidly adopt adequate, habitat-specific 
215 behaviours which, theoretically, could reduce mortality. Life cycle closure and habitat

216 connectivity between spawning and recruitment is believed to be under the direct 217 influence of variability in larval drift. Although larvae may drift to areas providing

218 survival into the juvenile stage, connectivity in the life cycle may be disrupted if those 219 juveniles do not encounter adults. As for habitat availability, the major characteristic of 220 connectivity was the large inter-annual variability (Table 2, column 3 ).

European anchovy: climate change impact in the Bay of Biscay

For anchovy in the Bay of Biscay, different models constructed for different life stages predicted an expansion of the population to the north under scenarios of climate change (Petitgas et al., 2009a). An increase in temperature throughout the year may influence the potential habitats of the adults towards a more northern distribution at spawning time. Winter unsuitability may decrease over the entire Bay of Biscay due to warmer temperatures but warmer summer temperatures associated with lower zooplankton production may increase the unsuitability of habitats in southern Biscay (Struski et al., 2009). An increase in temperature may shift peak spawning by one month earlier in the season (Petitgas et al., 2009a). In this situation and given current seasonal circulation patterns, the larvae may disperse more towards the north (Huret et $a l ., 2009)$. Under such a scenario, changes in the larval dispersion patterns could disrupt the current life cycle organisation in space and time. The survival probability of juveniles in novel areas is unknown as is the potential for connectivity with new adult habitats.

Thus, a warming climate is expected to increase habitat availability for spawning and juvenile stages, while its impact on larval and juvenile connectivity remain unknown because of potential changes in currents and spawning windows (Table 2, columns 4 and 5).

\section{Atlantic herring}

\section{Atlantic herring: habitat requirements}

Atlantic herring have specific habitat requirements for spawning. They are benthic spawners and deposit their eggs on solid substrates, whether this be course sand, gravel or boulders (Blaxter and Hunter, 1982; Geffen, 2009). In the Baltic, they also spawn on macro-algae or mussel beds (Casini, 2010). Herring generally spawn in areas of wellmixed water and it can be assumed that they require high oxygen saturation (Parrish et 
al., 1959; Aneer, 1985). They display great plasticity in spawning habitats across the species (Geffen 2009), thus, although individual populations may utilize specific habitats, overall habitat requirements for spawning are quite broad. Atlantic herring populations can be found spawning in all months of the year (Dickey-Collas et al., 2009a) and have a relatively wide temperature tolerance for spawning (4-15 ${ }^{\circ} \mathrm{C}$ : Pörtner and Peck, 2010; Peck et al., 2012). Salinity has been correlated to the genetic subspecies structure of Atlantic herring but, across the species, herring can spawn from 4 to 35 salinity units (Gaggiotti et al., 2009). They are generally thought to have predictable migration routes and spawning site fidelity (Sinclair, 1988), in which learning plays an important role (McQuinn, 1997; Petitgas et al., 2010b). However, this is not always the case as the location of spawning sites for Norwegian Spring spawning herring change as the fish get older and longer (Slotte, 1999). Thus, habitat requirements for spawning could be considered limiting for a herring population in a particular area.

Across the species, herring larvae can grow in temperatures from 2 to $21{ }^{\circ} \mathrm{C}$ (Oeberst et al., 2009; Pörtner and Peck, 2010) and across a wide range of salinities. Specific populations may have more specific requirements. Higher prey requirements at warmer temperatures may limit survival of larvae after yolk absorption in areas of relatively low prey production.

The temperature requirements for juveniles do not appear different from those of the larvae (Röckmann et al., 2011). Salinity requirements seem broad. Juveniles in the North Sea tend to be found in less saline water than the larvae (their nursery areas are generally shallow $<50 \mathrm{~m})$. However, nursery areas of the Norwegian spring-spawning herring are offshore in deeper waters of the Barents Sea (e.g., Holst et al., 2004).

The main factors that determine adult feeding habitats are zooplankton biomass, hydrography and seabed substrate in the North, Norwegian and Baltic seas (Maravelias and Reid, 2000; Nøttestad et al., 2007; Peltonen et al., 2007). These three factors often co-vary spatially (Maravelias, 2001).

Thus overall, adult feeding and juvenile habitats were considered 'broad", but those of eggs and young were classified as "narrow" (Table 3, column 1).

Atlantic herring: habitat availability in the North Sea

The availability of suitable spawning habitat for North Sea herring is limited to specific areas of appropriate substrate (see above). North Sea spawning beds are limited 
to the western areas and the English Channel (Dickey-Collas, 2010). A gradient exists

283 in the timing of spawning by North Sea herring with earlier (autumn) spawning occurring in the north, and later (winter) spawning in the south. There is some evidence that the timing of spawning by location is related to temperature-specific windows of optimal prey requirement for the larvae. Herring larvae individual-based model (IBM) simulations suggested that North Sea temperatures in summer are too high to support the survival of newly-hatched larvae at current levels of prey availability and that those individuals released in Orkney/Shetland do not have the opportunity to survive if spawned in November or December (Hufnagl and Peck, 2011). Therefore, although the physical habitat for the larvae is widely available, the availability of optimal habitats would be very restricted to time periods and locations having sufficient prey to meet larval metabolic requirements and ensuring the avoidance of predator hotspots. In contrast, habitats required for juveniles and adults are largely non-specific and are widely available in the North Sea (Dickey-Collas, 2010). Thus, habitat availability was considered 'small' for spawning adults and eggs, 'variable' for larvae and 'ok' for feeding adults and juveniles (Table 3, column 2).

Atlantic herring: connectivity to next stage in the North Sea

Beyond substrate requirements, spawning habitats are limited to areas that are upstream of the juvenile nursery grounds since larval and post-larval transport is primarily through drift (Heath et al., 1997; Dickey-Collas et al., 2009b). During these early life stages, transport is governed by prevailing water currents that, in turn, can be altered by atmospheric or oceanographic phenomena. This connectivity has long been postulated to control recruitment success in herring (Isles and Sinclair, 1982). Transport and retention interact with the degree of spatial overlap with prey and predators to determine how successfully larvae are "connected" to juvenile nursery grounds (larvae cannot merely be transported, they must also grow and survive).

In the case of the northern North Sea, larvae are occasionally entrained in northward flowing currents and are transported to the central coastline of Norway

311 (Fossum and Moksness, 1993) where they mix with spring-spawned larvae of

312 Norwegian / fjordic populations. The fate of these autumn-spawned larvae is unknown

313 (i.e. whether they are adopted into the Norwegian spring spawning populations or die,

314 or return to the North Sea). There is evidence that late larvae and juveniles from the 315 stocks to the west of the British Isles utilise portions of the northern North Sea as 
nursery areas (Heath, 1989; ICES, 1994). Again, the fate of these fish is unknown (i.e. whether they return to their parent stock, die or become North Sea herring by adoption).

Connectivity of the adults (multiple and first spawners) to the spawning grounds is crucial as herring show conservatism in migration and are thought to "learn" migration routes (Corten, 2001; Huse et al., 2010). Even when spawning beds are physically damaged or eradicated (e.g. by gravel extraction or closing the Zuiderzee) herring keep returning to the location of these beds, until the spawning groups die off (de Groot, 1980). Likewise, when herring are removed from historic spawning grounds (e.g. by over fishing), it can take many decades to re-establish spawning in those areas (Corten, 1999; Schmidt et al., 2009; Dickey-Collas et al., 2010). This is a core part of the life cycle closure in herring (Petitgas et al., 2010b) and appears most sensitive to disruption.

Therefore the migration to the spawning grounds was considered crucial while larval connectivity from egg to juvenile habitats was considered 'ok' or 'variable' (Table 3, column 3).

Atlantic herring: climate change impact in the North Sea

Although North Sea herring is close to its southern-most boundary in the Northeast Atlantic (the Bay of Biscay), little evidence exists to suggest that an increase in sea temperature of 1 to $2{ }^{\circ} \mathrm{C}$, will reduce the suitable habitat for the species, since the range in tolerable temperatures is broad (up to $20{ }^{\circ} \mathrm{C}$ in the Baltic). However the mortality of larvae does co-vary with increasing temperature in the northern North Sea (Fässler et al. 2011) suggesting that temperature may impact on productivity. As herring spawn layers of benthic eggs, any reduction in dissolved oxygen, through less mixing, increased eutrophication, etc., is expected to decrease egg survival. Also, the higher prey requirements after yolk absorption associated with warmer temperatures may indirectly limit the spatial and temporal extent of habitats allowing larval survival. Temperature is also expected to affect the growth of juveniles and adults with cohorts experiencing warmer temperature growing faster and reaching a smaller asymptotic size than individuals within cohorts growing at colder temperatures (Brunel and DickeyCollas, 2010). How this would affect overall population productivity remains unclear.

346 In relation to a changing growth pattern the spawning strategy could be impacted: it has been suggested that an increase in temperature favours the autumn spawning strategy in western Atlantic herring stocks (Melvin et al., 2009) and Hufnagl and Peck (2011) show 
zooplankton production cycle. Whether life history closure is possible given a different spawning strategy and a changed zooplankton production cycle is unknown.

352 Furthermore, an increase in biodiversity in the North Sea (e.g., increase in anchovy and sardine) may also introduce competition for pelagic habitats due to overlap in zooplankton diet (Raab et al., 2012). Overall, habitat availability in a changed climate is not expected to be limiting but habitats utilized may possibly shift towards higher latitudes (Table 3, column 4).

For most of the herring life stages, the impact of climate change on connectivity is unclear. Regional models are currently unable to predict the likely impact(s) of global climate change on the oceanography of the North Sea (see discussion). Thus, it is difficult to project the future influence of climate change on the transport of larvae or the location of adult feeding grounds with any confidence. Therefore, the impact of climate change on connectivity is difficult to predict and remains largely unknown (Table 3, column 5).

\section{European plaice}

\section{European plaice: habitat requirements}

Plaice is a broadcast spawner that exhibits spawning site fidelity (Rijnsdorp and Pastoors, 1995; Hunter et al., 2003; Solmundsson et al., 2005). Spawning occurs at depths of 20 to $50 \mathrm{~m}$ from the Bay of Biscay in the south to Iceland and the Barents Sea in the north (Wimpenny, 1953). Spawning shifts from December and January in the southern areas to April and May in more northerly ones (Harding et al., 1978; Gunnarsson et al., 2010) and is affected by water temperatures experienced during gonad development and the spawning period (Nash and Geffen, 1999; Teal et al., 2008).

374 Eggs and larvae are pelagic for about 2 to 3 months (Ryland and Nichols, 1975; Fox et $a l ., 2003)$. The range in average conditions experienced and the range in tolerable temperatures and salinities change with successive life stages. Juveniles are collected at warmer temperatures (from 3 to $18^{\circ} \mathrm{C}$ ) than eggs $\left(5\right.$ to $7{ }^{\circ} \mathrm{C}$ ), larvae $\left(4\right.$ to $6{ }^{\circ} \mathrm{C}$ ) or settlers $\left(3\right.$ to $6{ }^{\circ} \mathrm{C}$ ) and can tolerate warmer temperatures $\left(2\right.$ to $\left.22{ }^{\circ} \mathrm{C}\right)$ compared to eggs $(2$ to $12^{\circ} \mathrm{C}$ : Ryland et al., 1975; Fonds et al., 1992). Adults, eggs and larvae occur in seawater, whereas settlers and juveniles can occur in estuarine waters (20-32 psu) (Jager et al., 1993). Successful spawning only occurs in waters $>15$ psu (Nissling et al., 2002). 
384

associated increase in predation mortality (e.g., Harding et al., 1978; van der Veer, 1985; Seegers et al., 2007).

Plaice larvae feed on prey items abundant in the winter such as the appendicularian Oikopleura dioica (Shelbourne, 1953; Last, 1978). There are no studies reporting the importance of a match-mismatch between the timing of plaice spawning and food availability nor on the presence of potential predators on eggs and larvae (e.g. herring and sprat). Around metamorphosis, larvae become demersal and settle onto nursery grounds which are generally inshore, shallow ( $<10 \mathrm{~m}$ deep), sandy or muddy areas (e.g. Able et al., 2005; Gunnarsson et al., 2010). During settlement, the temporal and spatial overlap with predators is a key, temperature-dependent match-mismatch process affecting the survival of plaice settlers (post-larvae) in shallow nursery habitats (van der Veer and Bergman, 1987). Juvenile plaice feeds on a variety of macrobenthic species (de Vlas, 1979) while larger demersal stages mainly feed on polychaetes and molluscs (Rijnsdorp and Vingerhoed, 2001). As they grow, plaice gradually disperse from shallow coastal nurseries into deeper water. After maturation they seasonally migrate between spawning and feeding grounds. Demersal stages of plaice have a clear preference for soft sediments with a grain size of coarse to very fine sand (e.g. Gibson and Robb, 2000).

Thus overall, habitat requirements at the juvenile stage seem more restricted than for other life stages, for which requirements are "medium" (Table 4, column 1). Yet, populations living in areas such as the Baltic Sea where the ratio of adult to juvenile habitat is much lower may also experience density-dependent regulation of survival in other life history stages (Rijnsdorp, 1994).

\section{Plaice: habitat availability in the North Sea}

The extent of suitable habitats for post-larvae (during settlement) is much smaller than that of the earlier or later life history stages and the total population abundance of plaice seems to be related to the availability of suitable settlement nursery grounds (Rijnsdorp et al., 1992; van der Veer et al., 2000). Density-dependent processes are restricted to the phase where plaice are concentrated in nearshore nursery grounds (Beverton 1995; Nash and Geffen, 2000; van der Veer et al., 2000). Nursery ground quality will be affected by the productivity of suitable benthic food and by the abundance of potential predators (see above). Except for the 0-group, no correlation exists between inter-annual variability in growth rate and water temperatures (Rijnsdorp 
and van Leeuwen, 1996; Teal et al., 2008). Growth variability therefore seems to be determined by variations in benthic productivity due to variations in ocean climate, eutrophication and the effect of bottom trawling or habitat modification (Rijnsdorp and van Leeuwen, 1996). Suitable sediment types and polychaete/ mollusc prey of larger juveniles and adults are widely available throughout the North Sea. Over the last 20 years, juvenile and adult plaice have shifted to deeper and more northern areas likely in response to warming (van Keeken et al., 2007; Engelhard et al., 2011b).

Thus habitat availability at the early juvenile (post-larval) stage appears to be a critical bottleneck in the life cycle due to density-dependent processes, match-mismatch with predators and benthic productivity (Table 4, column 2). Larger juveniles and adults are not considered to experience restricted habitat availability in the North Sea despite recent shifts.

\section{Plaice: connectivity to next stage in the North Sea}

The offshore spawning areas are clearly separated from inshore nursery grounds.

433 Closure of the life cycle through connectivity is dependent on the passive drift of eggs, 434 pelagic larval drift on residual currents, and the onshore transport of post-larvae by 435 bottom currents, which may be enhanced by selective tidal stream transport (Rijnsdorp 436 et al., 1985; van der Veer et al., 1998; Bolle et al., 2009). For the other life stages, 437 connectivity does not seem to be a major control factor. The juveniles gradually 438 disperse into deeper water and will find a large area of suitable habitat open to them. 439 Feeding habitat for adults, which mainly occur in waters between $30-80 \mathrm{~m}$, are large and 440 widely dispersed, although their suitability may be restricted by the distance to 441 spawning areas, and the possibilities of using tidal streams of sufficient speed to 442 enhance migration opportunities (Hunter et al., 2003; 2004). For plaice, connectivity 443 between the spawning and the nursery grounds, therefore, is expected to be the critical 444 phase. This inference is corroborated by a number of observations. First, it has been 445 shown that the size of nursery habitat determines overall population abundance in 446 flatfish (Rijnsdorp et al., 1992; van der Veer et al., 2000). Second, the abundance of 0447 group plaice was positively correlated with the transport success as modelled with a 3D 448 hydrodynamic model using observed meteorological conditions and actual river 449 discharges (Bolle et al., 2009). Thus connectivity at the larval stage from spawning to 450 nursery grounds was considered crucial for successful life cycle closure (Table 4, 451 column 3). 
Plaice: climate change impact in the North Sea

With an increase in temperature under climate change scenarios and because plaice in the North Sea is at the southern-most end of its latitudinal range, the suitable habitat for egg production (spawning locations) is expected to become smaller. Similarly, with increased temperatures the available habitat for juveniles (nursery grounds) is also expect to decrease. The reduction in habitats will be detrimental to productivity and may lead to a reduced population size in the North Sea. In contrast, the connectivity between the pelagic phase and the nursery grounds (deemed as the crucial part of life cycle closure) will probably not change substantially although changes in currents are difficult to predict (see discussion). Moreover the production of O. dioica, which is the main prey item of plaice larvae, depends upon picoplankton and can be expected to be positively affected by temperature. Climate-driven match-mismatch of plaice and their prey is unlikely to be an important factor in determining later life stages (juveniles and adults). Therefore climate change is expected to reduce habitat suitability and availability at early juvenile stage and for spawning (Table 4, columns 4 and 5).

\section{Atlantic cod}

\section{Atlantic cod: habitat requirements}

Cod are multiple batch spawners with most stocks spawning between February and May, although some stocks spawn as early as January and some as late as August. The earlier spawners tend to inhabit the warmer, more southern regions of the North Atlantic (Fox et al., 2008). Adults exhibit spawning site fidelity, and thus appear to have specific habitat requirements for spawning (e.g. Wright et al., 2006; Sundby and Nakken, 2008). Depending on the stock and location, spawning sites occur at depths between 20 and $300 \mathrm{~m}$ (Brander, 2005). Temperatures during spawning are stock dependent and range from slightly below zero to $10{ }^{\circ} \mathrm{C}$ (Brander, 2005). The same temperatures support embryo survival (Geffen et al., 2006). The consistency in annual spawning times among stocks (Ellertsen et al., 1989) suggests that temperature may not be a dominant factor affecting spawning times.

The spawned eggs are typically found in upper surface waters. Drift patterns of eggs and larvae depend upon the stock. In some cases these early life stages are transported $>1000 \mathrm{~km}$ from spawning grounds (Vikebø et al., 2007) while, in other 
grounds (Hinrichsen et al., 2002) or within tidal mixing or river plume fronts (Munk et $a l ., 2009)$. Drift characteristics depend upon shelf topography, prevailing winds and drift duration (affected via temperature-specific development rates) (Vikebø et al., 2005).

Although the range of tolerable temperatures for cod larvae are considered broad (Fahay et al., 1999; Pörtner et al., 2008), larval growth and survivorship are governed, to a large extent, by match-mismatch dynamics occurring between larvae and their prey. The prey consumed by larval cod varies among populations (Heath and Lough, 2007) but larval growth rates increase with increasing temperature and photoperiod, with the latter having a stronger influence in years of high prey abundance (Otterlei et al., 1999; Suthers and Sundby, 1996; Buckley et al., 2006). Prey-limited growth has also been documented for larval cod in the field (Buckley and Durbin, 2006). Also warmer temperatures have a higher impact on the larvae energy requirements compared to later life stages (Peck and Buckley, 2007).

After metamorphosis, pelagic juveniles undergo settlement and alter their diet to become generalists (Dalpadado and Bogstad, 2004). Juveniles tend to prefer shallower areas than adults and can be found over a wider range of temperatures than larvae and adults (Fahay et al., 1999). In many regions, juveniles preferentially use structured habitats as refuges from predation (Gotceitas et al., 1995; Cote et al., 2004), but can spread out to more open areas if no such structures are available (Ciannelli et al., 2007; Dingsør et al., 2007). Younger individuals may inhabit less optimal conditions (colder temperatures) to avoid predation, including cannibalism (Ciannelli et al., 2007; Dingsør et al., 2007).

Large juveniles and adult cod have broad habitat requirements and are generalist predators feeding on benthic and demersal prey. Adult cod have very broad diets that can include smaller conspecifics but generally reflect availability of local resources

512 (Daan, 1974). Even for the more northern cod stocks that rely more heavily on single 513 forage species such as capelin (Mallotus villosus), when those prey are scarse, adult cod 514 will switch to other species including crustaceans. Overall, this implies broad habitat 515 requirements for adults during the feeding season. They also have a broad thermal tolerance (Righton et al., 2010) although adult NEA cod historically spawned within a narrow range in water temperatures $\left(5-7^{\circ} \mathrm{C}\right.$ : Brander, 2005). Tagging studies indicate

518 that adults of many stocks disperse over wide areas to feed but make very directed 519 migrations to specific spawning grounds (Righton et al., 2007; Hobson et al., 2009). 
Thus overall, habitat requirements seem broad at adult and juvenile stage, while they are smaller at larval stage and for spawning (Table 5, column 1).

Atlantic cod: habitat availability in the Norwegian/Barents seas

Important aspects of habitat availability for cod are the presence of key prey for larvae, specific thermal windows allowing growth (Pörtner et al., 2008), and the ability of juveniles to escape predation pressure during and shortly after settlement (Juanes, 2007).

Habitat availability is likely restricted during larval stage, owing to the specific zooplanktonic prey requirements, which for the Northeast Arctic (NEA) cod is Calanus finmarchicus (Sundby, 2000). Correlations between the abundances of sequential life stages are generally high until the larval period, indicating that critical processes operate during that stage (Sundby et al., 1989; Helle et al., 2000). Predation pressure on aggregations of juvenile cod can be very intense and localised and be critical to recruitment (Temming et al., 2007). Thus, availability of structured (protective) habitat may act as a density-dependent bottleneck that potentially limits the survival of juveniles (pre-recruits).

Although large juveniles and adult cod have broad habitat requirements, their habitats in the Barents Sea may be restricted due to the importance of capelin in their diets. Although NEA cod adjust their diets and take what is available, the production of cod and abundance of capelin are strongly correlated. However, habitat requirements of earlier life stages (eggs to small juveniles) are potentially more limiting.

Thus, we considered habitat availability variable or occasionally limiting at the larval stage (Table 5, column 2) and not limiting for the other life stages.

\section{Atlantic cod: connectivity to next stage in the Norwegian/Barents Sea}

The transport of eggs and larvae from the spawning sites to the nursery grounds over a 2 to 3 month period is of primary importance and the stock shows structure based on that constraint. Cod in the eastern Barents Sea generally spawn in the coastal areas from Lofoten northwards, while the western Barents Sea and West Spitzbergen component spawn farther offshore and in the areas south of Lofoten (Randa, 1984; Godø, 1986; Vikebø et al., 2007). Later on, during the demersal phase, juveniles and feeding adults are capable of active migrations, with adults known to range over many hundreds of kilometres (Godø and Michalsen, 2000). Hence the connectivity between 
554 these later life stages is not considered as problematic. However long-distance 555 migrations are energetically costly, imposing trade-offs between reproductive output 556 and the distance that can be covered to reach profitable feeding sites (Jørgensen and 557 Fiksen, 2006). From the above, we considered that variability in larval connectivity was 558 a major characteristic in cod life cycle closure (Table 5, column 3).

559

\section{Atlantic cod: climate change impacts in the Norwegian/Barents Sea}

Given the projected increases in water temperature, suitable habitats for cod are expected to increase in the Barents and Norwegian Seas (Drinkwater, 2005). Climatedriven changes in the dispersion and survival of cod eggs and larvae appear to be most critical for population-level impacts. Further, climate change may influence the matchmismatch dynamics between larvae and key prey including C. finmarchicus (Heath and Lough, 2007).

Habitat availability may be less limiting during the juvenile to adult stages, and there is evidence that growth and condition are positively affected by warmer temperatures across most of the species' range (Brander 1995; Dutil and Brander, 2003). Climate warming may therefore improve individual juvenile and adult growth conditions, although this could be offset if prey abundance decreases. On the population level, improved growth conditions could be offset by declines in recruitment or increased predation on early life-stages. Climate change and increased water temperatures are expected to cause increase productivity in NEA cod as conditions for the population will improve (Drinkwater, 2005; Cheung et al., 2008).

For the NEA cod, changes in the dispersion of cod larvae and juveniles northward to nursery grounds in the Barents Sea and West Spitzbergen may be critical. Climatedriven changes in advective transport and mixing will affect dispersion and ultimately the distribution of the cod, but also the temperatures they are exposed to en route, which in turn will affect their growth rates (Vikebø et al., 2005). Changes in the larval dispersal pattern may result from changes in the location and time of spawning, water currents and vertical and horizontal mixing. Whether the impact of altered transport processes will be positive or negative cannot be determined at this time. Furthermore, it is unclear whether cod can 'adapt' to changing hydrological conditions by shifting their spawning sites. However, the relative importance of northerly compared to southerly spawning areas of NEA cod has increased considerably during earlier and current warm 
2008). We consider connectivity between the demersal life stages of cod to be less sensitive to climate change because these stages have higher mobility and broader habitat requirements (i.e., diets, thermal range: Righton et al., 2010) than eggs and larvae. However, patterns of connectivity between habitats of later life stages could be altered by climate-driven physiological impacts.

Overall, we considered climate-driven changes at the egg and larval stages to be critical for NEA cod (Table 5) but, climate-driven changes in the connectivity patterns at the larval stage remain uncertain.

\section{TOWARDS A QUANTIFICATION OF THE ANALYSIS}

Because of the variety of the case studies and literature sources the qualitative categorizations can be difficult to assign or similar codes assigned for different reasons. To identify more precisely the sensitive features of the life cycle on which climate change may be impacting and thus confirm the qualitative coding performed, we attempted a more quantitative characterisation of the life cycles.. For that, we concentrated on temperature and food for characterizing habitat requirements, spatial extend for habitat availability and distance travelled for connectivity. Ranges of physiological tolerance to temperature were compared to that of conditions in their natural environment at the time when the particular life history stage occurs in the system. Food diversity was estimated as the Shannon-Wiener index (standardized to unity) based on literature and stomach sampling data. The rationale for including food diversity was that a high specificity in food requirements may be considered to enhance the sensitivity of a particular life stage to changes in the environment. The availability of suitable habitats for each life history stage was estimated by their spatial extent from observed distribution maps. The surface area of each stage was estimated as that at which $90 \%$ of the population of the stage occurred. Surface areas were standardized by

614 dividing by the largest area across the stages. Connectivity was estimated based on 615 geographical distance travelled using the distance between the gravity centres of the 616 habitats of successive life history stages. Distances were standardised to the typical 617 body size of each life history stage, and the connectivity was expressed as the $618 \log _{10}(1 /$ distance $)$. Geographical displacement is the resultant of many interactions 619 including the behavioural use of currents, temperature mediated duration of the drift or 620 migration, and energy expenditure of individuals. We considered that, whatever the underlying mechanisms, precise connectivity was less probable when travelling over 
622 long distances and therefore made a direct link between distance travelled and 623 connectivity. The methodology was applied to North Sea plaice and Bay of Biscay 624 anchovy as these species populations had the most contrasting life histories (Figs. 2 and $6253)$.

626 For North Sea plaice (Fig. 2) habitat requirements (temperature range and food 627 diversity) are more restrictive for the early life stages than for juveniles and adults, in 628 particular because of the restrictive food regime of the larvae in winter. The juveniles 629 show the smallest spatial availability for habitats because of the specific requirements 630 for shallow coastal muddy sediments hosting particular invertebrates as food. The 631 connectivity during the larval stage between spawning grounds and nursery grounds is 632 the lowest across the life cycle and appears to be a weak point. This more quantitative 633 analysis agrees with the qualitative categorization made previously (Table 4). The life 634 cycle shows narrow habitat availability at larval and early juvenile stage as well as strict 635 connectivity at larval stage between spawning and nursery grounds. These 636 characteristics of the life cycle could be the sensitive features by which climate change 637 may impact North Sea plaice. Also, the minimum and maximum temperatures 638 experienced are slightly under and over the limits of the physiological tolerance range, 639 meaning that variability between years can also be the means by which climate change 640 is impacting.

641 In contrast, Biscay anchovy life cycle shows few bottlenecks (Fig. 3) as 642 temperature and food requirements are broad and available. The juvenile stage is the 643 most dispersed. The life cycle is predominantly characterized by a loose connectivity as 644 larvae, juveniles and adults drift / migrate long distances, which is compatible with a 645 large potential for dispersion over large suitable areas. Again, this quantification agrees 646 with the previous qualitative analysis (Table 2) where habitats were considered broadly 647 available and connectivity variable. In contrast to Biscay anchovy, North Sea plaice 648 shows more restrictions in habitats and a more restrictive connectivity. These two 649 contrasting examples give insight on how changes in habitat availability or connectivity 650 pathways can result in changes in the organisation of life cycles and thus population 651 dynamics.

652

653 DISCUSSION

654

Life cycle summaries and identification of sensitive features 
In this study we developed a generic framework to characterize the full life cycle of fish populations and identify sensitive features to evaluate how life cycles as a whole could be modified by climate change. We considered all life history stages, their habitats and connectivity between them. The output of the procedure was a qualitative coding of habitat requirements, availability, and connectivity. We also included examples of how metrics of different life history stages could be expressed quantitatively. The approach allows a comparison of life cycle sensitivity to climate change among populations by explicitly including the environmental characteristics experienced within different systems.

To further identify sensitive features of specific populations from our life cycle categories (Tables 2 to 5), we summed the number of "narrow" (requirements), "small" (habitat availability) and "crucial" (connectivity) categories within tables; these assessments corresponded to constraints in the life cycles (Table 6). Based upon these sums, North Sea plaice and herring had more habitat bottlenecks (narrow requirements or crucial availability) in their life cycles than did either Bay of Biscay anchovy or Norwegian/Barents sea cod. Bay of Biscay anchovy and North Sea plaice were at two extremes in terms of their ability to cope with environmental change. While Biscay anchovy shows broad habitat requirements and flexible connectivity with high dispersion, North Sea plaice has strict habitat requirements for both spawners and young juveniles making connectivity a sensitive feature of its life cycle.

\section{Linking life cycle characteristics to potential climate change impacts}

The analysis of the life cycles identified two major, sensitive features: (i) whether there was narrow habitat availability for a particular life stage representing a bottleneck in the life cycle, and (ii) whether the life cycle closure depended upon strict connectivity at larval stage that adults must strictly compensate strictly in space and time by a "contranatant" migration and corresponding spawning site fidelity and phenology.

683 Changes in environmental conditions may reduce habitat availability and changes in ocean circulation may disrupt connectivity pathways and life cycle closure. Thus to link the sensitive features of the life cycles to the potential impacts of climate change, we scored by summing across the rows of Tables 2 to 5 the categories "smaller" or "shift" (impact on habitat availability) as these represented negative impacts on habitats. Similarly, we scored the category "?" (impact on connectivity) as this category represented uncertainty in expert judgement (Table 6). 
North Sea plaice was assigned the most number of bottlenecks in its life cycle, the most negative impacts of climate change on habitats, and least uncertainty in climate impact on connectivity. This analysis, therefore, suggests that the probability is high that North Sea plaice will be impacted by climate change. North Sea herring was also assigned the most bottlenecks in its life cycle, but less negative impacts of climate change on its habitats and more uncertainty in the influence of climate change on its connectivity. Therefore, there is also an expectation of negative impacts of climate change on North Sea herring. On the other hand, Bay of Biscay anchovy and NEA cod were assigned none or few bottlenecks in their life cycle, less negative impacts of climate change on habitats, and more uncertainty on the impact of climate change on connectivity. Therefore the life cycle of these populations are not expected to be impacted negatively by climate change. They may benefit from climate change with increased habitat availability and stock productivity (Drinkwater, 2005; Stenevik and Sundby, 2007; Petitgas et al., 2009a).

The response of life cycles as a whole to climate change involves many interactions. The space-time matching of the schedule of key events in life cycles with the seasonality in the environment (involving, e.g. flow fields and vertical stratification, growth and maturation patterns, match-mismatch between predators and prey in all life history stages: Dickey-Collas et al., 2009b; Peck et al., 2009; Petitgas et al., 2009b; van der Veer and Bergman, 1987) may be disrupted by climate change. If changes in habitat availability for the various life stages under climate change can be predicted, leading to maps of potential new distributions, the role of connectivity in the life cycle reorganisation should not be overlooked as it may contradict these predictions.

713 Connectivity may be a limiting factor in successful adaptation of the species under

714 climate change. From our analysis, schematics of the global response based on the interaction between changes in habitats and connectivity pathways (Table 7) suggest that North Sea plaice could become a small, contracted population while the other populations could change their distribution patterns if newly available habitats are effectively colonized.

\section{Uncertainties in the predictions}

We developed a generic framework for assembling and categorizing knowledge from the literature. Following the approach developed for dealing with complexity when assessing risk in ecosystem management (e.g., Samhouri and Levin, 2012) we 
attempted to convert qualitative categorizations (expert judgement) into quantitative indicators (Figs. 2 and 3, Table 6) that served as a basis for conclusions. In doing so, major uncertainties were identified. The impact of climate change on larval connectivity was the greatest unknown. Changes in ocean currents and larval drift routes and dispersion could either disrupt life cycle closure (Fig. 1d, Table 7) or lead to the establishment of new life cycle patterns. The closure of the life cycle by larval dispersion results from many interactions during the species life history and their adequate seasonal scheduling, of which favourable patterns of ocean circulation, growth pattern and predator-prey interactions are most critical.

Ocean circulation and seasonality. Due to the importance of larval connectivity in the vast majority of marine fish species, predicting future changes will depend upon the ability to adequately project climate-driven changes in water circulation at regional scale. Projections of water circulation patterns arising from climate change are available for areas such as the North Sea by dynamic downscaling of global climate models (GCMs) to force a regional circulation model (Ådlandsvik, 2008). However, much more work is required to provide robust projections (Hollowed et al., 2009). Furthermore, progress in quantitatively predicting regional population responses to climate-driven changes will require the development of spatially-explicit full life cycle models. In addition, advances in modelling bioenergetic budgets, trophic interactions and behaviour will be necessary for the development of full life-cycle population models in an end-to-end context to simulate the evolution of fish populations in different climate change scenarios.

Trophic interactions. The match-mismatch dynamics between predators and their prey were considered important in all species and populations (during one life history stage at least) by altering survival and rates of growth and energy storage which ultimately affects recruitment or fecundity and connectivity pathways. Furthermore, warming will increase metabolic requirements, potentially changing the outcome of match-mismatch dynamics between predators and preys, growth and maturity patterns, and ultimately connectivity pathways between habitats of different life history stages.

Regional physiological adaptations. The species considered in this analysis were examined within a single system but are distributed across a range of different systems. Their genetic diversity has undoubtedly allowed for regional adaptation. Stage-specific requirements at the level of the species could be large because of the diversity in regional adaptations. Our appreciation of changes in habitat availability for a given 
758 population in a regional sea did not account for regional adaptations, which is another

759 factor limiting projections of regional-scale population responses to rapid climate 760 change.

761

\section{CONCLUSION}

763 In summary, recognising that fish populations have complex life cycles that 764 comprise different stages exploiting a variety of habitats, we analysed how climate 765 change could impact the links along the life cycle. We developed a framework to 766 understand the drivers on life cycle patterns, which considered habitat requirements in 767 the different life stages at species level, habitat availability in specific ecoregions and 768 connectivity to the next stage in these systems (Fig. 1). We reviewed the knowledge 769 available for 4 species in 3 marine ecosystems and summarized results in tables 770 structured to reflect the life cycle framework (Tables 2 to 5). The analysis is generic and 771 can be applied to any specific population to analyse changes in its life cycle pattern. The 772 present review highlighted that: i) larval connectivity represented a major unknown and

773 ii) projecting climate change impacts on fish populations while disregarding life cycle 774 organization could lead to spurious conclusions as conflicting impacts on habitats and connectivity need be resolved in the different life stages. Thus, full life cycle models are seen as the most adequate tools to integrate the different impacts of climate across all

777 life stages.

\section{ACKNOWLEDGEMENTS}

780 This study was partly financed by the EU project RECLAIM (FP6 contract 044133). 781 


\section{REFERENCES}

Able, K.W., Neuman, M.J. and Wennhage, H. (2005) Ecology of juvenile and adult stages of flatfishes: distribution and dynamics of habitat associations. In: Flatfishes: biology and exploitation. R.N. Gibson (ed.) London: Blackwell Science, pp. 164184.

Ådlandskvik, B. (2008) Marine downscaling of a future climate scenario for the North Sea. Tellus 60A: 451-458.

Aldonando, N., Cotano, U., Tiepolo, M., Boyra, G. and Irigoien, X. (2010) Growth and movement patterns of early juvenile European anchovy (Engraulis encrasicolus L.) in the Bay of Biscay based on otolith microstructure and chemistry. Fish. Oceanogr. 19: 196-208.

Allain, G., Petitgas, P., Lazure, P. and Grellier, P. (2007) Biophysical modelling of larval drift, growth and survival for the prediction of anchovy (Engraulis encrasicolus) recruitment in the Bay of Biscay (NE Atlantic). Fish. Oceanogr. 16: 489-505.

Aneer, G. (1985) Some speculations about the Baltic Herring (Clupea harengus membras) in connection with the eutrophication of the Baltic Sea. Can. J. Fish. Aquat. Sci. 42S1: 83-90.

Beaugrand, G. (2004) The North Sea regime shift: evidence, causes, mechanisms and consequences. Progr. Oceanogr. 60: 245-262.

Bergeron, J.P. (2004) Contrasting years in the Gironde estuary (Bay of Biscay, NE Atlantic) springtime outflow and consequences for zooplankton pyruvate kinase activity and the nutritional condition of anchovy larvae: an early view. ICES J. Mar. Sci. 61: 928-932.

Bergeron, J.P. (2009) Nutritional condition of anchovy Engraulis encrasicolus larvae in connection with mesozooplankton feeding catabolism in the southern Bay of Biscay, NE Atlantic. J. Exp. Mar. Biol. Ecol. 377: 76-83.

Beverton, R.J.H. (1995) Spatial limitation of population size: the concentration hypothesis. Neth. J. Sea Res. 34: 1-6

814 Bolle, L.J., Dickey-Collas, M., Beek, van J.K.L., Erftemeijer, P.L.A., Witte, J.IJ., Veer, 815 van der H.W. and Rijnsdorp, A.D. (2009) Variability in transport of fish eggs and 
larvae. III. The effects of hydrodynamics and larval behaviour on recruitment in plaice. Mar. Ecol. Prog. Ser. 390: 195-211.

Brander, K.M. (1995) The effects of temperature on growth of Atlantic cod (Gadus morhua L.). ICES J. Mar. Sci. 52: 1-10.

Brander, K.M. (2005) Spawning and life history information for North Atlantic cod stocks. ICES Coop. Res. Rep. No. 274: 152pp.

Buckley, L.J., Caldarone, E.M., Lough, R.G. and St. Onge-Burns, J.M. (2006) Ontogenetic and seasonal trends in recent growth rates of Atlantic cod and haddock larvae on Georges Bank: effects of photoperiod and temperature. Mar. Ecol. Prog. Ser. 325: 205-226.

Buckley, L.J., and Durbin, E.D. (2006) Seasonal and inter-annual trends in the zooplankton prey and growth rate of Atlantic cod (Gadus morhua) and haddock (Melanogrammus aeglefinus) larvae on Georges Bank. Deep-Sea Res. II 53: 27582770.

Bulgakova, Y. (1992) Intensity of feeding of the Black Sea anchovy Engraulis encrasicolus during the spawning season. J. Ichthyol. 32: 168-171.

Brunel, T. and Dickey-Collas, M. (2010) Effects of temperature and population density on von Bertalanffy growth parameters in Atlantic herring growth: a macroecological analysis. Mar. Ecol. Prog. Ser. 405: 15-28.

Casini, M. 2010. Baltic herring. In: Life cycle spatial patterns of small pelagic fish in the Northeast Atlantic. P. Petitgas (ed.) ICES Coop. Res. Rep. No. 326: 31-33.

Cheung, W., Lam, V., and Pauly, D. (2008) Dynamic bioclimate envelope model to predict climate-induced changes in distribution of marine fishes and invertebrates. pp:5-50. In: Modelling Present and Climate-Shifted Distribution of Marine Fishes and Invertebrates. W. Cheung, V. Lam and D. Pauly (eds) Fisheries Centre Research Reports 16(3): 5-50.

Ciannelli, L., Dingsør, G.E., Bogstad, B., Ottersen, G., Chan, K.S., Gjøsæter, H., and Stenseth, N.C. (2007) Spatial anatomy of species survival: effects of predation and climate-driven environmental variability. Ecology 88: 635-646.

Corten, A. (2001) The role of "conservatism" in herring migrations. Rev. Fish Biol. Fish. 11: 339-361

Corten, A. (1999) The reappearance of spawning herring on Aberdeen Bank in 1983 and its relationship to environmental conditions. Can. J. Fish. Aquat. Sci. 56: 20512061. 
850 Cote, D., Moulton, S., Framption, P., Scruton, D.A., and McKinley, R.S. (2004) Habitat

851

852

853

854

855

856

857

858

859

860

861

862

863

864

865

866

867

868

869

870

871

872

873

874

875

876

877

878

879

880

881

882 use and early winter movements by juvenile Atlantic cod in a coastal area of Newfoundland. J. Fish Biol. 64: 665-679.

Daan, N. (1974) A quantitative analysis of the food intake of North Sea cod, Gadus morhua. Neth. J. Sea Res. 6: 479-517.

Dalpadado, P. and Bogstad, B. (2004) Diet of juvenile cod (age 0-2) in the Barents Sea in relation to food availability and cod growth. Polar Biol. 27: 140-157.

de Groot, S.J. (1980) The consequences of marine gravel extraction on the spawning of herring, Clupea harengus Linne. J. Fish Biol. 16: 605-611.

de Vlas, J. (1979) Annual food intake by plaice and flounder in a tidal flat area in the Dutch Wadden Sea, with special reference to consumption of regenerating parts of macrobenthic prey. Neth. J. Sea Res. 13: 117-153.

Diaz, E., Txurruka, J.M. and Villate, F. (2008) Biochemical composition and condition in anchovy larvae Engraulis encrasicolus during growth. Mar. Ecol. Prog. Ser. 361: 227-238.

Dickey-Collas, M. (2010) North Sea herring. In: Life cycle spatial patterns of small pelagic fish in the Northeast Atlantic. P. Petitgas (ed.) ICES Coop. Res. Rep. No. 326: 7-18.

Dickey-Collas, M., Bolle, L.J., van Beek, J.K.L. and Erftemeijer, P.L.A. (2009b) Variability in transport of fish eggs and larvae. II. The effects of hydrodynamics on the transport of Downs herring larvae. Mar. Ecol. Prog. Ser. 390: 183-194

Dickey-Collas, M., Clarke, M., and Slotte, A. (2009a) "Linking Herring": do we really understand plasticity? ICES J. Mar. Sci. 66: 1649-1651.

Dickey-Collas, M., Fox, C.J., Nash, R.D.M. and O'Brien, C.M. (2003) Plaice egg mortality: can we determine survivorship? J. Sea Res. 50: 211-225.

Dickey-Collas, M., Nash, R.D.M., Brunel, T., van Damme, C.J.G., Marshall, C.T., Payne, M.R., Corten, A., Geffen, A.J., Peck, M.A., Hatfield, E.M.C., Hintzen, N.T., Enberg, K., Kell, L.T., and Simmonds, E.J. (2010) Lessons learned from stock collapse and recovery of North Sea herring: a review. ICES J. Mar. Sci. 67: 18751886.

Dingsør, G.E., Ciannelli, L., Chan, K-S., Ottersen, and Stenseth, N.C. (2007) Density dependence and density independence during early life stages of four marine fish stocks. Ecology 88: 625-634. 
883 Drinkwater, K.F. (2005) The response of cod (Gadus morhua) to future climate change. ICES J. Mar. Sci. 62: 1327-1337.

Dubreuil, J. and Petitgas, P. (2009) Energy density of anchovy Engraulis encrasicolus in the Bay of Biscay. J. Fish Biol. 74: 521-534.

Dutil, J.D., and Brander, K.M. (2003) Comparing productivity of North Atlantic cod (Gadus morhua) stocks and limits to growth production. Fish. Oceanogr. 12: 502512.

Ellertsen, B., Fossum, P., Solemdal, P. and Sundby, S. (1989) Relations between temperature and survival of eggs and first feeding larvae of Northeast Arctic cod (Gadus morhua L.). Rapp. P.-V. Réun. Cons. Int. Explor. Mer 191: 209-219.

Engelhard, G.H., Ellis, J.R., Payne, M.R., ter Hofstede, R. and Pinnegar, J.K. (2011a) Ecotypes as a concept for exploring responses to climate change in fish assemblages. ICES J. Mar. Sci. 68: 580-591.

Engelhard, G.H., Pinnegar, J.K., Kell, L.T. and Rijnsdorp, A.D. (2011b) Nine decades of North Sea sole and plaice distribution. ICES J. Mar. Sci. 68: 1090-1104.

Fahay, M. P., Berrien, P. L., Johnson, D.L. and Morse, W.W. (1999) Essential fish habitat source document: Atlantic cod, Gadus morhua, life history and habitat characteristics US NOAA Technical Memorandum NMFS-NE-124: 41 pp.

902

Fässler, S.M.M., Payne, M.R., Brunel, T. and Dickey-Collas, M (2011) Does larval

Fonds, M., Cronie, R., Vethaak, A.D. and Puyl, P.V.D. (1992) Metabolism, food consumption and growth of plaice (Pleuronectes platessa) and flounder (Platichthys flesus) in relation to fish size and temperature. Neth. J. Sea Res. 29: 127-143.

Fossum, P. and Moksness, E. (1993) A study of spring- and autumn-spawned herring (Clupea harengus L.) larvae in the Norwegian coastal current during spring 1990. Fish. Oceanogr. 2: 73-81.

910 Fox, C.J., Geffen, A.J., Blyth, R., and Nash, R.D.M. (2003) Temperature-dependent 911 development rates of plaice (Pleuronectes platessa L.) eggs from the Irish Sea. J. $912 \quad$ Plankton Res. 25: 1319-1329.

913 Fox, C.J., M. Taylor, M. Dickey-Collas, P. Fossum, G. Kraus, N. Rohlf, P. Munk, 914 C.J.G. van Damme, L.J. Bolle, D.L. Maxwell, J. Peter and Wright, P.J. (2008) 915 Mapping the spawning grounds of North Sea cod (Gadus morhua) by direct and 916 indirect means. Proc. R. Soc. B 275: 1543-1548. 
917 Gaggiotti, O.E. Bekkevold, D., Jørgensen, H.B.H., Foll, M. Carvalho, G.R., Andre, C.

918 and Ruzzante, D.E. (2009) Disentangling the effect of evolutionary, demographic

919 and environmental factors influencing genetic structure of natural populations:

$920 \quad$ Atlantic herring as a case study. Evolution 63: 2939-2951.

921 Geffen, A.J. (2009) Advances in herring biology: from simple to complex, coping with

922 plasticity and adaptability. ICES J. Mar. Sci. 66: 1688-1695.

923 Geffen, A.J., Fox, C.J. and Nash, R.D.M. (2006) Temperature-dependent development

924 rates of cod Gadus morhua eggs. J. Fish Biol. 69: 1060-1080.

925 Gibson, R.N. and Robb, L. (2000) Sediment selection in juvenile plaice and its 926 behavioural basis. J. Fish Biol. 56: 1258-1275.

927 Godø, O.R. (1986) Dispersion and mingling of cod from various nursery and feeding 928 areas along the Norwegian coast and in the Barents Sea. In: Workshop on 929 comparative biology, assessment, and management of gadoids from the North 930 Pacific and Atlantic Oceans. M. Alton (ed.) Seattle: Northwest Alaska Fisheries 931 Center, pp. 663-672.

932 Godø, O.R., and Michalsen, K. (2000) Migratory behaviour of north-east Arctic cod, 933 studied by the use of data storage tags. Fish. Res. 48: 127-140.

934 Gotceitas, V., Fraser, S. and Brown, J.A. (1995) Habitat use by juvenile Atlantic cod 935 (Gadus morhua) in the presence of an actively foraging and non-foraging predator. $936 \quad$ Mar. Biol. 123: 421-430.

937 Gunnarsson, B., Jonasson, J.P. and McAdam, B.J. (2010) Variation in hatch date 938 distributions, settlement, and growth of juvenile plaice (Pleuronectes platessa L.) in 939 Icelandic waters. J. Sea Res. 64: 61-67.

940 Harden-Jones, F. R. (1968) Fish Migration. London: Edward Arnold.

941 Harding, D., Nichols, J.H. and Tungate, D.S. (1978) The spawning of the plaice 942 (Pleuronectes platessa L.) in the southern North Sea and English Channel. Rapp. P.943 V. Réun. Cons. Int. Explor. Mer 172: 102-113.

944 Heath, M.R. (1989) Transport of larval herring (Clupe harengus L.) by the Scottish 945 coastal current. Rapp. P-V. Réun. Cons. Int. Explor. Mer 191: 85-91.

946 Heath, M.R. and Lough, R.G. (2007) A synthesis of large-scale patterns in the 947 planktonic prey of larval and juvenile cod (Gadus morhua). Fish. Oceanogr. 16: $948 \quad 169-185$.

949 Heath, M.R., Scott, B. and Bryant, A.D. (1997) Modelling the growth of herring from 950 four different stocks in the North Sea. J. Sea Res. 38: 413-436. 
951

952

953

954

955

956

957

958

959

960

961

962

963

964

965

966

967

968

969

970

971

972

973

974

975

976

977

978

979

980

981

982

983

Helle, K., Bogstad, B., Marshall, C. T., Michalsen, K., Ottersen, G. and Pennington, M. (2000) An evaluation of recruitment indices for Arcto-Norwegian cod (Gadus morhua L.). Fish. Res. 48: 55-67.

Hinrichsen, H.H., Möllmann, C., Voss, R., Köster, F. and Kornilovs G. (2002) Biophysical modeling of larval Baltic cod (Gadus morhua) growth and survival. Can. J. Fish. Aquat. Sci. 59: 1858-1873.

Hobson, V.J., Righton, D., Metcalfe, J.D., and Hays, G.C. (2009) Link between vertical and horizontal movement patterns of cod in the North Sea. Aquat. Biol. 5: 133-142.

Holst, J.C., Røttingen, I. and Melle, W. (2004) The herring. In: The Norwegian ecosystem. H.R. Skjoldal, R. Sætre, A. Færnö, A.O. Misund and I. Røttingen (eds). Trondheim: Tapir Academic Press, pp. 203-226.

Hufnagl, M. and Peck, M.A. (2011) Physiological-based modelling of larval Atlantic herring (Clupea harengus) foraging and growth: Insights on climate-driven life history scheduling. ICES J. Mar. Sci. 68 : 1170-1188.

Hollowed, A.B., Bond, N.A., Wilderbuer, T.K., Stockhausen, W.T., A'mar, Z.T., Beamish, R.J., Overland, J.E. and Schirripa, M.J. (2009) A framework of modelling fish and shellfish responses to future climate change. ICES J. Mar. Sci. 66: 15841594.

Hunter, E., Metcalfe, J.D., Arnold, G.P. and Reynolds, J.D. (2004) Impacts of migratory behaviour on population structure in North Sea plaice. J. Anim. Ecol. 73: 377-385.

Hunter, E., Metcalfe, J.D. and Reynolds, J.D. (2003) Migration route and spawning area fidelity by North Sea plaice. Proc. Roy. Soc. London B 270: 2097-2103.

Huret, M., Petitgas, P. and Léger, F. (2009) Sensitivity of anchovy larval dispersal to climate variability of the Bay of Biscay. ICES CM 2009/E:08.

Huret, M., Petitgas, P. and Woillez, M. (2010) Dispersal kernels and their drivers captured with a hydrodynamic model and spatial indices: a case study on anchovy (Engraulis encrasicolus) early life stages in the Bay of Biscay. Progr. Oceanogr. 87: 6-17.

Huse, G., Fernö, A. and Holst, J.C. (2010) Establishment of new wintering areas in herring co-occurs with peaks in the "first time/repeat spawner" ratio. Mar. Ecol. Prog. Ser. 409: 189-198.

ICES. 1994. Report of the study group on herring assessment and biology in the Irish Sea and adjacent waters. ICES CM 1994/H:5. 
984

985

986

987

988

989

990

991

992

993

994

995

996

997

998

999

1000

1001

1002

1003

1004

1005

1006

1007

1008

1009

1010

1011

1012

1013

1014

1015

1016

ICES. 2009. Report of the Benchmark Workshop on Short-lived Species (WKSHORT). ICES CM2009/ACOM:34.

Iles, T.D. and Sinclair, M. (1982) Atlantic herring: stock discreteness and abundance. Science 215: 627-633

Irigoien, X., Fiksen, Ø., Cotano, U., Uriarte, A., Alvarez, P., Arrizabalaga, H., Boyra, G., Santos, M., Sagarminaga, Y., Otheguy P., Etxebeste E., Zarauz, L., Artetxe, I., and Motos L. (2007) Could Biscay Bay anchovy recruit through a spatial loophole? Progr. Oceanogr. 74: 132-148.

Irigoien, X., Cotano, U., Boyra, G., Santos, M., Alvarez, P., Uriarte, A., Ferrer, L. and Ibaibarriaga, L. (2008) From egg to juvenile in the Bay of Biscay: spatial patterns of anchovy (Engraulis encrasicolus) recruitment in a non-upwelling region. Fish. Oceanogr. 17: 446-462.

Jager, Z., Kleef, H.L. and Tydeman, P. (1993) The Distribution of O-group flatfish in relation to abiotic factors on the tidal flats in the brackish Dollard (Ems Estuary, Wadden Sea). J. Fish Biol. 43: 31-43.

Jørgensen, C. and Fiksen, Ø. (2006) State-dependent energy allocation in cod (Gadus morhua). Can. J. Fish. Aquat. Sci. 63: 186-199.

Juanes, F. (2007) Role of habitat in mediating mortality during the post-settlement transition phase of temperate marine fishes. J. Fish Biol. 70: 661-677.

Kanstinger, P. and Peck, M.A. (2009) Co-occurrence of European sardine (Sardina pilchardus), anchovy (Engraulis encrasicolus) and sprat (Sprattus sprattus) larvae in southern North Sea habitats: Abundance, distribution and biochemical-based condition. Scient. Mar. 73S1: 141-152.

Koutsikopoulos, C. and Le Cann, B. (1996) Physical processes and hydrological structures related to the Bay of Biscay ancvhovy. Scient. Mar. 60S2: 9-19.

La Mesa, M., Donato, F., Giannetti, G. and Arneri, E. (2009) Growth and mortality rates of European anchovy (Engraulis encrasicolus) in the Adriatic Sea during the transition from larval to juvenile stages. Fish. Res. 96: 275-280.

Last, J.M. (1978) The food of four species of pleuronectiform larvae in the eastern English Channel and southern North Sea. Mar. Biol. 45 : 359-368.

Maravelias, C.D. (2001) Habitat associations of Atlantic herring in the Shetland area: influence of spatial scale and geographic segmentation. Fish. Oceanogr. 10: 259267. 
1017 Maravelias, C.D. and Reid D.G. (2000) Seabed substrate, water depth and zooplankton 1018 as determinants of the prespawning spatial aggregation of North Atlantic herring. Mar. Ecol. Prog. Ser. 195: 249-259.

1020 Marquis, E., Petitgas, P., Niquil, N. and Dupuy, C. (2006) Influence of the small pelagic 1021 fish on the structure and functioning of the planktonic food web on the continental 1022 shelf of the Bay of Biscay. ICES CM 2006/F:09.

1023 McQuinn, I.H. (1997) Metapopulations and the Atlantic herring. Rev. Fish Biol. Fish. 7: $1024 \quad 297-329$.

1025 Melvin, G.D., Stephenson, R.L. and Power, M.J. (2009) Oscillating reproductive

Motos, L., Uriarte, A. and Valencia, V. (1996) The spawning environment of the Bay of Biscay anchovy (Engraulis encrasicolus, L.). Scient. Mar. 60S2: 117-140.

Munk, P., Fox, C.J., Bolle, L.J., van Damme, C.J.G., Fossum, P. and Kraus, G. (2009) Spawning of North Sea fishes linked to hydrographic features. Fish. Oceanogr. 18: 458-469.

Nash, R.D.M. and Geffen, A.J. (1999) Variability in Stage I egg production and settlement of plaice Pleuronectes platessa on the west side of the Isle of Man, Irish Sea. Mar. Ecol. Prog. Ser. 189: 241-250.

Nash, R.D.M. and Geffen, A.J. (2000) The influence of nursery ground processes in the determination of year-class strength in juvenile plaice Pleuronectes platessa L. in Port Erin Bay, Irish Sea. J. Sea Res. 44: 101-110.

Nissling, A., Westin, L. and Hjerne, O. (2002) Reproductive success in relation to salinity for three flatfish species, dab (Limanda limanda), plaice (Pleuronectes platessa), and flounder (Pleuronectes flesus), in the brackish water Baltic Sea. ICES J. Mar. Sci. 59: 93-108.

Nøttestad, L., Misund, O.A., Melle, W,. Ulvestad, B.K.H. and Orvik, K.A. (2007) Herring at the Arctic front: influence of temperature and prey on their spatiotemporal distribution and migration. Mar. Ecol. 28S1: 123-133.

Oeberst, R., Dickey-Collas, M. and Nash, R.D.M. (2009) Mean daily growth of herring larvae in relation to temperature over a range of $5-20^{\circ} \mathrm{C}$, based on weekly repeated cruises in the Greifswalder Bodden. ICES J. Mar. Sci. 66: 1696-1701.

Otterlei, E., Nyhammer, G., Folkvord, A. and Stefansson, S.O. (1999) Temperature- and size-dependent growth of larval and early juvenile Atlantic cod (Gadus morhua): a 

comparative study of Norwegian coastal cod and northeast Arctic cod. Can. J. Fish. Aquat. Sci. 56: 2099-2111.

Ottersen, G. and Sundby, S. (2005) Norwegian Arctic cod. In: Spawning and life history information for North Atlantic cod stocks. ICES Coop. Res. Rep. 274: 11-18.

Parrish, B.B., Saville, A., Craig, R.E., Baxter, I.G. and Priestley, R. (1959) Observations on herring spawning and larval distribution in the Firth of Clyde in 1958. J. Mar. Biol. Assoc. U.K. 38: 445-453.

Peck, M.A. and Buckley, L.J. (2007) Measurements of larval Atlantic cod (Gadus morhua) routine metabolism and individual-based modeling. J. Appl. Ichthyol. 24: $1-6$.

Peck, M.A., Kanstinger, P., Holste, L. and Martin, M. (2012) Thermal windows supporting survival of the earliest life stages of Baltic herring (Clupea harengus). ICES J Mar Sci 69 (4): 529-536.

Peck, M.A., Kühn, W. and Hinrichsen, H.-H. (2009) Inter-annual and inter-specific differences in the drift of fish eggs and yolksac larvae in the North Sea: A biophysical modeling approach. Scient. Mar. 73S1: 23-36.

Pecquerie, L., Petitgas, P. and Kooijman, S. (2009) Modeling fish growth and reproduction in the context of the Dynamic Energy Budget theory to predict environmental impact on anchovy spawning duration. J. Sea Res. 62: 93-105.

Peltonen, H., Luoto, M., Pääkkönen, J.P., Karjalainen, M., Tuomaala, A., Pönni, J. and Viitasalo, M. (2007) Pelagic fish abundance in relation to regional environmental variation in the Gulf of Finland, northern Baltic Sea. ICES J. Mar. Sci. 64: 487-495.

Petitgas, P. (2007) Bay of Biscay anchovy: do adults facilitate the adoption by recruits of schooling behaviour and habitat occupation? In: Report of the workshop on testing the entrainment hypothesis (WKTEST). ICES CM 2007/LRC:10, pp. 89-95 (Annex 10).

Petitgas, P., Alheit, J., Peck, M.A., Raab, K., Irigoien, X., Huret, M., van der Kooij, J., Pohlmann, T., Wagner, C., Zarraonaindia, I. and Dickey-Collas, M. (2012) Anchovy population expansion in the North Sea. Mar. Ecol. Prog. Ser. 444: 1-13

Petitgas, P., Huret, M. and Struski, C. (2009a) Anchovy in the Bay of Biscay. In: Report on the effects of future climate change on key fish and shellfish stock distribution, migration pattern, growth and reproduction. K. Drinkwater (ed.) EU project RECLAIM Deliverable D4.3. http://www.climateandfish.eu/. 
1084

1085

1086

1087

1088

1089

1090

1091

1092

1093

1094

1095

1096

1097

1098

1099

1100

1101

1102

1103

1104

1105

1106

1107

1108

1109

1110

1111

1112

1113

1114

1115

1116

Petitgas, P., Huret, M., Léger, F., Peck, M.A., Dickey-Collas, M., Rijnsdorp, A.D. (2009b) Patterns and schedules in hindcasted environments and fish life cycles. ICES CM 2009/H:25.

Petitgas, P., Secor, D., McQuinn, I., Huse, G., and Lo, N. (2010b) Stock collapses and their recovery: mechanisms that establish and maintain life-cycle closure in space and time. ICES J. Mar. Sci. 67: 1841-1848.

Petitgas, P., Uriarte, A., Nogueira, E., Massé, J. and Cotano, U. (2010a) Bay of Biscay anchovy. In: Life cycle spatial patterns of small pelagic fish in the Northeast Atlantic. ICES Coop. Res. Rep. 306: 40-44.

Planque, B., Bellier, E. and Lazure, P. 2007. Modelling potential spawning habitat of sardine (Sardina pilchardus) and anchovy (Engraulis encrasicolus) in the Bay of Biscay. Fish. Oceanogra. 16: 16-30.

Plounevez, S. and Champalbert, G. (1999) Feeding behaviour and trophic environment of Engraulis encrasicolus (L.) in th Bay of Biscay. Estuar. Coast. Shelf Sci. 49: 177191.

Pörtner, H.O., Bock, C., Knust, R., Lannig, G., Lucassen, M., Mark, F.C. and Sartoris, F.J. (2008) Cod and climate in a latitudinal cline: physiological analyses of climate effects in marine fishes. Clim. Res. 37: 253-270.

Pörtner, H.O. and Peck, M.A. (2010) Climate change effects on fishes and fisheries: towards a cause-and-effect understanding. J. Fish Biol. 77: 1745-1779.

Raab, K., Nagelkerke, L.A.J., Boerée, C., Rijnsdorp, A.D., Temming, A., and Dickey-Collas, M. (2011) Anchovy Engraulis encrasicolus diet in the North and Baltic Seas. J. Sea Res. 65: 131-140.

Raab, K., Nagelkerke, L.A.J., Boerée, C., Rijnsdorp, A.D., Temming, A. and DickeyCollas, M. (2012) Dietary overlap between the potential competitors herring, sprat and anchovy in the North Sea. Mar. Ecol. Prog. Ser. doi 10.3354/meps09919

Randa, K. (1984) Abundance and distribution of O-group Arcto-Norwegian cod and haddock 1965-1982. In: Reproduction and recruitment of Arctic cod. O.R. Godø and S. Tilseth (eds) Proc. Soviet-Norwegian Bergen: Symp. Institute Mar. Res., pp. 189-210.

Righton, D.A., Andersen, K.H., Neat, F., Thorsteinsson, V., Steingrund, P., Svedäng, H., Michalsen, K., Hinrichsen, H.-H., Bendall, V., Neuenfeldt, S., Wright, P., Jonsson, P., Huse, G., van der Kooij, J., Mosegaard, H., Hüssy, K. and Metcalfe, J. 
1117

1118

1119

1120

1121

1122

1123

1124

1125

1126

1127

1128

1129

1130

1131

1132

1133

1134

1135

1136

1137

1138

1139

1140

1141

1142

1143

1144

1145

1146

1147

1148

1149

1150

(2010) Thermal niche of Atlantic cod Gadus morhua: limits, tolerance and optima. Mar. Ecol. Prog. Ser. 420: 1-13.

Righton, D., Quayle, V.A., Hetherington, S. and Burt, G. (2007) Movements and distribution of cod (Gadus morhua) in the southern North Sea and English Channel: results from conventional and electronic tagging experiments. J. Mar. Biol. Assoc. UK 87: 599-613.

Rijnsdorp, A.D., Peck, M.A., Engelhard, G.H., Möllmann, C. and Pinnegar, J.K. (2009) Resolving the effect of climate change on fish populations. ICES J. Mar. Sci. 66: $1570-1583$.

Rijnsdorp, A.D. (1994) Population regulating processes during the adult phase in flatfish. Neth. J. Sea Res. 32: 207-223.

Rijnsdorp, A.D. and Pastoors, M.A. (1995) Modelling the spatial dynamics and fisheries of North Sea plaice (Pleuronectes platessa L.) based on tagging data. ICES J. Mar. Sci. 52: 963-980.

Rijnsdorp, A.D., van Beek, F.A., Flatman, S., Miller, J.M., Riley, J.D., Giret, M. and de Clerk, R. (1992) Recruitment of sole, Solea solea (L.), in the Northeast Atlantic. Neth. J. Sea Res. 29: 173-192.

Rijnsdorp, A.D. and van Leeuwen, P.I. (1996) Changes in growth of North Sea plaice since 1950 in relation to density, eutrophication, beam-trawl effort, and temperature. ICES J. Mar. Sci. 53: 1199-1213.

Rijnsdorp, A.D., van Stralen, M. and van der Veer, H.W. (1985) Selective tidal transport of North Sea plaice larvae Pleuronectes platessa in coastal nursery areas. Trans. Am. Fish. Soc. 114: 461-470.

Rijnsdorp, A.D. and van der Veer, H.W. (2010) Plaice. In: Resolving climate impacts on fish stocks. ICES Coop. Res. Rep. 301: 187-192.

Rijnsdorp, A.D. and Vingerhoed, B. (1994) The ecological significance of geographical and seasonal differences in egg size in sole Solea solea (L.). Neth. J. Sea Res. 32: 255-270

Rijnsdorp, A.D. and Vingerhoed, B. (2001) Feeding of plaice, Pleuronectes platessa, and sole Solea solea in relation to the effects of bottom trawling. J. Sea Res. $\mathbf{4 5}$ : 219-230

Röckmann, C., Dickey-Collas, M., Payne, M.R. and van Half, R. (2011) Realised habitats of early-stage North Sea herring: looking for signals of environmental change. ICES J. Mar. Sci. 68: 537-546. 
1151 Ryland, J.S. and Nichols, J.H. (1975) Effect of temperature on the embryonic 1152 development of the plaice, Pleuronectes platessa L. (Teleostei). J. Exp. Mar. Biol. Ecol. 18: 121-137.

1154 Samhouri, J.F. and Levin, P.S. (2012) Linking land- and sea-based activities to risk in coastal ecosystems. Biol. Conserv. 145: 118-129.

1156 Schmidt, J.O., van Damme, C.J.G., Röckmann, C. and Dickey-Collas, M. (2009)

1157 Recolonisation of spawning grounds in a recovering fish stock: recent changes in 1158 North Sea herring. Scient. Mar. 73(S1): 1253-157.

1159 Seegers, F.H.I.D., Dickey-Collas, M., Rijnsdorp, A.D. (2007) Prey selection by North 1160 Sea herring (Clupea harengus), with special reference to fish eggs. ICES J. Mar. Sci. 64: 60-68

Shelbourne, J.E. (1953) The feeding habits of plaice post-larvae in the Southern Bight. J. Mar. Biol. Assoc. UK 32: 149-159.

1164 Slotte A. (1999) Effects of fish length and condition on spawning migration in Norwegian spring spawning herring (Clupea harengus L.). Sarsia 84: 111-127.

Sinclair, M. (1988) Marine Populations: an essay on population regulation and speciation. Seattle, University of Washington Press.

Solmundsson, J., Palsson, J., and Karlsson, H. (2005) Fidelity of mature Icelandic plaice (Pleuronectes platessa) to spawning and feeding grounds. ICES J. Mar. Sci. 62: 189-200.

Stenevik, E.K., and Sundby, S. (2007) Impacts of climate change on commercial fish stocks in Norwegian waters. Mar. Policy 31: 19-31.

Struski, C., Petitgas, P. and Huret, M. (2009) Long-term hindcast and climate change forecast of habitat unsuitability using bioenergetics and physical-biogeochemical models: anchovy in the Bay of Biscay and the North Sea. ICES CM 2009/E:22.

Sundby, S. (2000) Recruitment of Atlantic cod stocks in relation to temperature and advection of copepod populations. Sarsia 85: 277-298.

1178 Sundby, S., Bjoerke, H., Soldal, A.V. and Olsen, S. (1989) Mortality rates during the early life stages and year-class strength of the North-East Arctic cod (Gadus morhua L.). Rapp. P.-V. Réun. Cons. Int. Explor. Mer 191: 351-358.

1181 Sundby, S. and Nakken, O. (2008) Spatial shifts in spawning habitats of Arcto1182 Norwegian cod related to multidecadal climate oscillations and climate change. 1183 ICES J. Mar. Sci. 65: 953-962. 
1184 Suthers, I. M. and Sundby, S. (1996) Role of the midnight sun: comparative growth of 1185 pelagic juvenile cod (Gadus morhua) from the Arcto-Norwegian and a Nova 1186 Scotian stock. ICES J. Mar. Sci. 53: 827-836.

1187 Teal, L.R., de Leeuw, J.J., van der Veer, H.W. and Rijnsdorp, A.D. (2008) Effects of 1188 climate change on growth of 0-group sole and plaice. Mar. Ecol. Prog. Ser. 358: $1189 \quad 219-230$.

1190 Temming, A., Floeter, J. and Ehrich, S. (2007) Predation hot spots: large-scale impact 1191 of local aggregations. Ecosystems 10: 865-876.

1192 Tudela, S. and Palomera, I. (1997) Trophic ecology of the European anchovy Engraulis 1193 encrasicolus in the Catalan Sea (northwest Mediterrnean). Mar. Ecol. Prog. Ser. 1194 160: 121-134.

1195 Tudela, S., Palomera, I. and Quilez, G. (2002) Feeding of anchovy Engraulis 1196 encrasicolus larvae in the north-west Mediterannean Sea. J. Mar. Biol. Assoc. UK 1197 82: $349-350$.

1198 Urtizberea, A., Fiksen, Ø., Folkvord, A. and Irigoien, X. (2008) Modelling growth of 1199 larval anchovies including diel feeding patterns, temperature and body size. $J$. $1200 \quad$ Plankton Res. 12: 1369-1383.

1201 van der Veer, H.W. (1985) Impact of coelenterate predation on larval plaice 1202 Pleuronectes platessa and flounder Platichthys flesus stock in the western Wadden 1203 Sea. Mar. Ecol. Prog. Ser. 25: 229-238.

1204 van der Veer, H.W. and Bergman, M.J.N. (1987) Predation by crustaceans on a newly1205 settled 0-group plaice (Pleuronectes platessa L.) population in the western Wadden Sea. Mar. Ecol. Prog. Ser. 35: 203-215. van der Veer, H.W., Berghahn, R., Miller, J.M. and Rijnsdorp, A.D. (2000) Recruitment 1208 in flatfish, with special emphasis on North Atlantic species: progress made by the 1209 Flatfish Symposia. ICES J. Mar. Sci. 57: 202-215.

1210 van der Veer, H.W., Ruardij, P., van den Berg, A.J. and Ridderinkhof, H. (1998) Impact 1211 of interannual variability in hydrodynamic circulation on egg and larval transport of 1212 plaice Pleuronectes platessa L. in the southern North Sea. J. Sea Res. 39: 29-40.

1213 van Keeken, O.A., Van Hoppe, M., Grift, R.E. and Rijnsdorp, A.D. (2007) The 1214 implications of changes in the spatial distribution of juveniles for the management 1215 of North Sea plaice (Pleuronectes platessa). J. Sea Res. 57: 187-197 
1216 Vikebø, F., Jørgensen, C., Kristiansen, T., and Fiksen, Ø. (2007) Drift, growth, and 1217 survival of larval Northeast Arctic cod with simple rules of behaviour. Mar. Ecol. 1218 Prog. Ser. 347: 207-219.

1219 Vikebø, F., Sundby, S., Ådlandsvik, B., and Fiksen, Ø. (2005) The combined effect of 1220 transport and temperature on distribution and growth of larvae and pelagic juvinles 1221 of Arcto-Norwegian cod. ICES J. Mar. Sci. 62: 1375-1386.

1222 Werner, F.E., Perry, R.I., Lough, R.G. and Naimie, C.E. (1996) Trophodynamics and advective influences on Georges Bank larval cod and haddock. Deep-Sea Res. II 43: 1793-1822.

1226 Wright, P.J., Galley, E., Gibb, I.M. and Neat, F.C. (2006) Fidelity of adult cod to spawning grounds in Scottish waters. Fish. Res. 77: 148-158.

1228

1229

1230

1231

1232

1233

1234

1235

1236

1237

1238

1239

1240

1241

1242

1243

1244

1245

1246

1247

1248

1249 
Table 1: Summary of life history characteristics for the selected species populations

\begin{tabular}{|c|c|c|c|c|}
\hline & $\begin{array}{c}\text { Bay of Biscay } \\
\text { anchovy }\end{array}$ & $\begin{array}{l}\text { North Sea } \\
\text { herring }\end{array}$ & $\begin{array}{l}\text { North Sea } \\
\text { plaice }\end{array}$ & $\begin{array}{l}\text { North East Arctic } \\
\text { cod }\end{array}$ \\
\hline life span (y) & 4 & 17 & 25 & 17 \\
\hline $\operatorname{Lmax}(\mathrm{cm})$ & 20 & 35 & 60 & 200 \\
\hline maturation age $(\mathrm{y})$ & 1 & 3 & 3 & 6 \\
\hline $\begin{array}{l}\text { egg and larva } \\
\text { stage duration } \\
\text { (days) }\end{array}$ & 60 & 120 & 80 & 80 \\
\hline $\begin{array}{l}\text { distance travelled } \\
\text { from spawning to } \\
\text { nursery }(\mathrm{km})\end{array}$ & 220 & 300 & 250 & 1200 \\
\hline spawning period & April to July & Sept to Feb & Dec to March & Feb to April \\
\hline $\begin{array}{l}\text { reproductive } \\
\text { biology }\end{array}$ & $\begin{array}{l}\text { indeterminate } \\
\text { batch spawner }\end{array}$ & $\begin{array}{c}\text { determinate total } \\
\text { spawner }\end{array}$ & $\begin{array}{c}\text { determinate batch } \\
\text { spawner }\end{array}$ & $\begin{array}{c}\text { determinate batch } \\
\text { spawner }\end{array}$ \\
\hline preys of larvae & microzooplankton & microzooplankton & appendicularian & $\begin{array}{c}\text { nauplii } \\
\text { C.finmarchicus } \\
\end{array}$ \\
\hline preys of juveniles & $\begin{array}{c}\text { small } \\
\text { mesozooplankton }\end{array}$ & $\begin{array}{c}\text { small } \\
\text { mesozooplankton }\end{array}$ & $\begin{array}{c}\text { regenerating parts } \\
\text { of polychaetes, } \\
\text { bivalves }\end{array}$ & $\begin{array}{l}\text { capelin, fish, } \\
\text { invertebrates }\end{array}$ \\
\hline preys of adults & $\begin{array}{c}\text { copepods and } \\
\text { other } \\
\text { mesozooplankton }\end{array}$ & $\begin{array}{c}\text { copepods and } \\
\text { other } \\
\text { mesozooplankton }\end{array}$ & $\begin{array}{c}\text { polychaetes,bivalve } \\
\mathrm{s}\end{array}$ & $\begin{array}{l}\text { capelin, fish, } \\
\text { invertebrates }\end{array}$ \\
\hline $\begin{array}{l}\text { domain of eggs } \\
\text { then larvae }\end{array}$ & pelagic & $\begin{array}{c}\text { benthic then } \\
\text { pelagic }\end{array}$ & pelagic & pelagic \\
\hline $\begin{array}{l}\text { jdomain of uveniles } \\
\& \text { adults }\end{array}$ & pelagic & pelagic & benthic & demersal \\
\hline References & $\begin{array}{c}\text { Petitgas et al. } \\
2010 a\end{array}$ & $\begin{array}{c}\text { Geffen } 2009 \\
\text { Dickey-Collas } \\
2010 \\
\end{array}$ & $\begin{array}{c}\text { Rijnsdorp and van } \\
\text { der Veer } 2010 \\
\text { Bolle et al. } 2009 \\
\text { Last } 1978 \\
\text { de Vlas } 1979 \\
\text { Rijnsdorp and } \\
\text { Vingerhoed } 2001 \\
\end{array}$ & $\begin{array}{l}\text { Ottersen and } \\
\text { Sundby } 2005 \\
\text { Vikebo } 2005\end{array}$ \\
\hline
\end{tabular}


1265 Table 2: European anchovy in the Bay of Biscay. Table documenting how critical the life

1266 stages are in the life cycle. Habitat requirements are at species level. Habitat availability,

1267 connectivity and climate change impacts concern the Bay of Biscay only.

\begin{tabular}{llllll}
\hline Life history & Habitat & Habitat & Connectivity & Climate change & Climate change \\
stage & requirements & availability & to next stage & Habitat & Connectivity \\
& & & & availability & \\
& & & &
\end{tabular}

Spawning

Adults and

\begin{tabular}{lccccc} 
eggs & medium & ok & var & larger & ok \\
\hline Larvae & medium & var & var & ok & $?$ \\
\hline Juveniles & broad & var & var & larger, shift & $?$ \\
\hline Feeding adults & medium & var & ok & ok & ok \\
\hline
\end{tabular}

Table 3: Atlantic herring in the North Sea. Table documenting how critical the life stages are in the life cycle. Habitat requirements are at species level. Habitat availability, connectivity and climate change impacts concern the North Sea only.

\begin{tabular}{llllll}
\hline Life history & Habitat & Habitat & Connectivity & Climate change & Climate change \\
stage & requirements & availability & to next stage & Habitat & Connectivity \\
& & & & availability &
\end{tabular}

Spawning

Adults and

\begin{tabular}{lccccc} 
eggs & narrow & small & ok & shift & ok \\
\hline Larvae & narrow & var & var & & $?$ \\
\hline Juveniles & broad & ok & ok & larger, shift & ok \\
\hline Feeding adults & broad & ok & crucial & ok or ? & ok or ? \\
\hline
\end{tabular}


1282 Table 4: European plaice in the North Sea. Table documenting how critical different stages

1283 are in the life cycle. Habitat requirements are at species level. Habitat availability, connectivity

1284 and climate change impacts concern the North Sea only.

\begin{tabular}{llllll}
\hline Life history & Habitat & Habitat & Connectivity & Climate change & Climate change \\
stage & requirements & availability & to next stage & Habitat & Connectivity \\
& & & & availability & \\
& & & &
\end{tabular}

Spawning

Adults and

\begin{tabular}{lccccc} 
eggs & medium & ok & ok & smaller & ok \\
\hline Larvae & medium & ok & crucial & ok & $?$ \\
\hline Juveniles & narrow & small & ok & smaller, shift & ok \\
\hline Feeding adults & medium & ok & ok & ok & ok \\
\hline
\end{tabular}

1285

1286

1287 Table 5: Atlantic cod in the Barents and Norwegian Seas (North East Artic cod stock).

1288 Habitat requirements are at species level and thus the same as in Table 4a. Habitat availability

1289 and connectivity and climate change impacts concern the Barents and Norwegian Seas only.

\begin{tabular}{llllll}
\hline Life history & Habitat & Habitat & Connectivity & Climate change & Climate change \\
stage & requirements & availability & to next stage & Habitat & Connectivity \\
& & & & availability &
\end{tabular}

Spawning

Adults and

\begin{tabular}{lccccc} 
eggs & medium & ok & ok & ok & ok \\
\hline Larvae & medium & medium & ok & larger & $?$ \\
\hline Juveniles & narrow & var & var & larger & $?$ \\
\hline Feeding adults & broad & ok & ok & ok & ok
\end{tabular}


Table 6: Analysis of the life cycle tables for each species population (Tables 2 to 5): the

1301 scores correspond to the number of times a particular code was assigned over all the life history 1302 stages: number of constraints in the life cycle (out of 12), number of negative impacts (out of 4) 1303 and number of unknown impacts (out of 4).

1304

1305

1306

1307

1308

1309

1310

1311

1312

1313

1314

1315

1316

1317

1318

1319

1320

1321

1322

1323

\begin{tabular}{|l|l|l|l|}
\hline & $\begin{array}{l}\text { Constraints in life } \\
\text { cycle }\end{array}$ & $\begin{array}{l}\text { Climate change } \\
\text { negative impacts on } \\
\text { habitats }\end{array}$ & $\begin{array}{l}\text { Climate change } \\
\text { unknown impacts on } \\
\text { connectivity }\end{array}$ \\
\hline Bay of Biscay anchovy & 0 & 0 & 2 \\
\hline North Sea herring & 4 & 1 & 2 \\
\hline North Sea plaice & 4 & 2 & 1 \\
\hline NEA cod & 1 & 0 & 2 \\
\hline
\end{tabular}

Table 7: Expected population response to the interaction between changes in habitats availability and connectivity pathways.

\section{No Change in connectivity Change in connectivity}

\begin{tabular}{lll}
\hline No Change in Habitats & No change & Disruption of life cycle \\
\hline Expansion in Habitats & No change & Change in distribution \\
\hline Reduction in Habitats & Population reduction & Disruption of life cycle \\
\hline
\end{tabular}

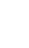


a)

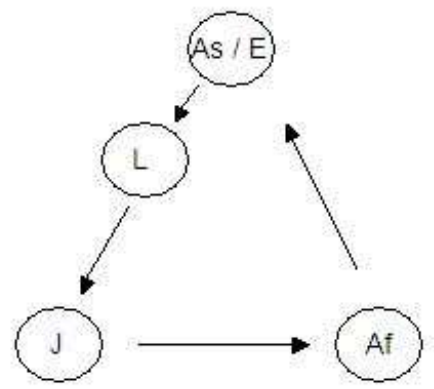

c)

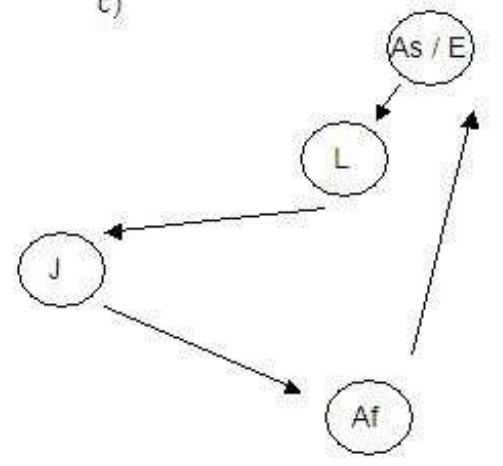

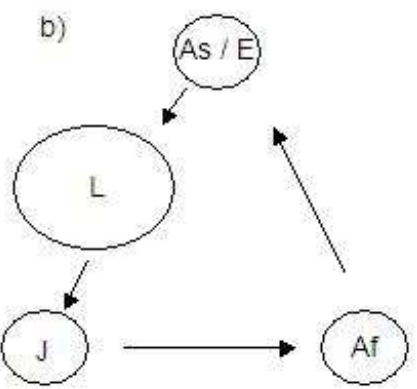

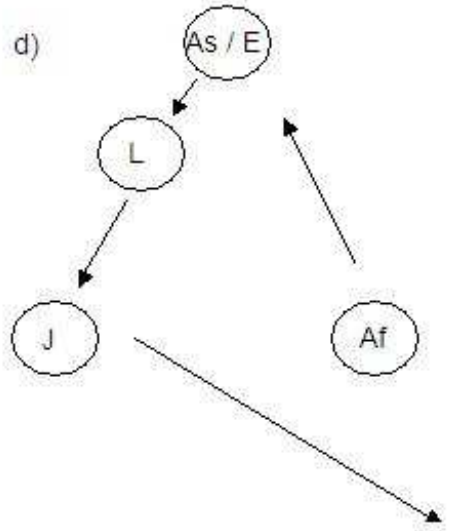

1328 Figure 1: Schematics of a life cycle (a) and different impacts of climate change on its organization (b-d). Impacts may concern habitat availability (b, the larger the bubble the greater the availability), a shift in the location of available habitats (c, the available habitat is spatially shifted from its position in comparison to scheme a) or disruption of connectivity (d, the life cycle cannot be closed). Af: feeding adults; As/E: spawning

1333 adults and eggs; L: larvae; J: juveniles. The bubble represents the size of the 1334 multidimensional available habitat. Each arrow represents connectivity to the next stage. 

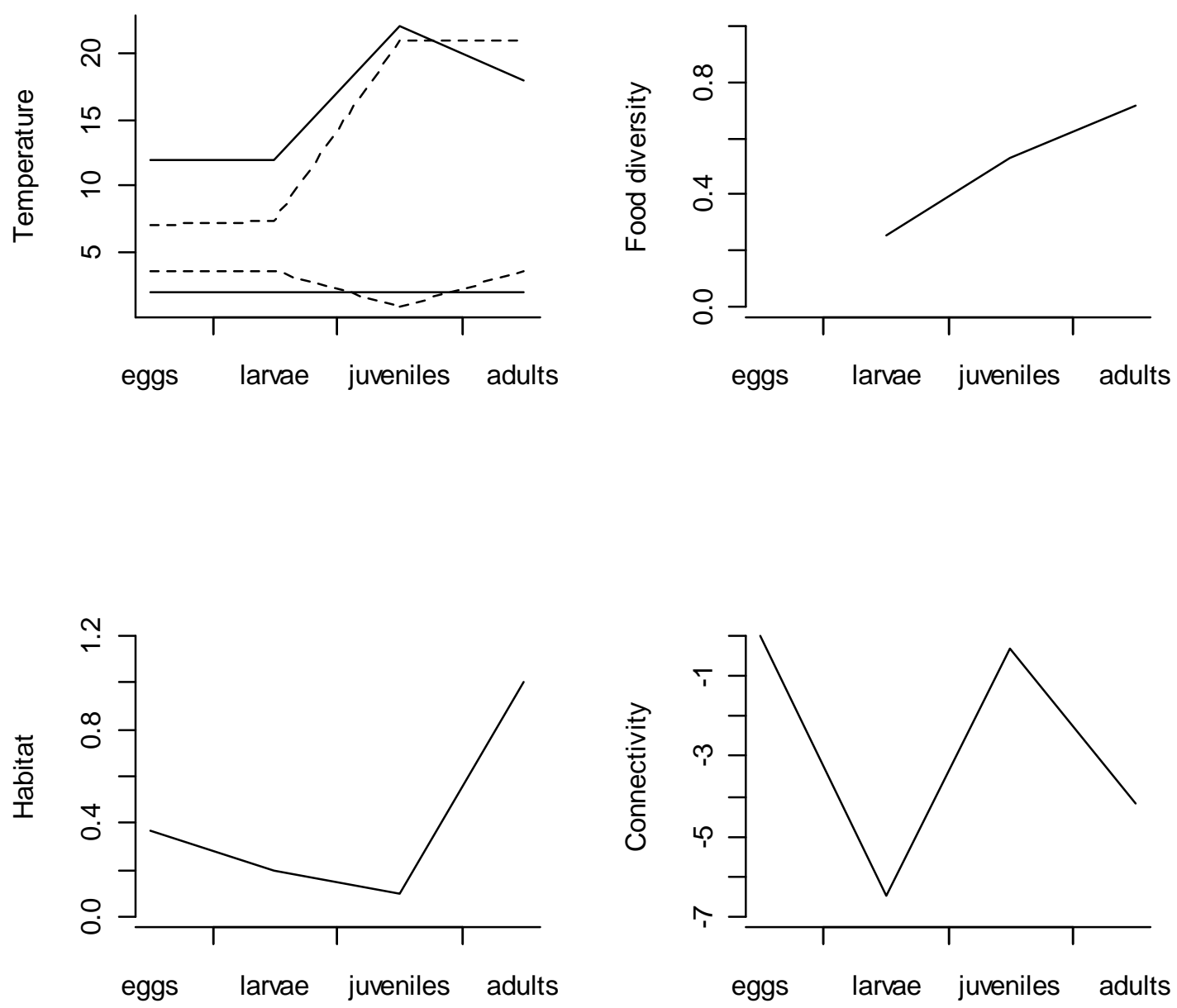

1345 Figure 2 : North Sea plaice life cycle quantified. Upper left: physiological tolerance

1346 range for temperature (full lines) and the temperature range observed (dashed lines).

1347 Upper right: food diversity (Shannon index standardized to unity). Lower left: habitat

1348 spatial availability referenced to the largest habitat across the life history stages. Lower

1349 right: connectivity between life history stages expressed as $\log 10(1 /$ distance travelled)

1350 where distance is in body length. 

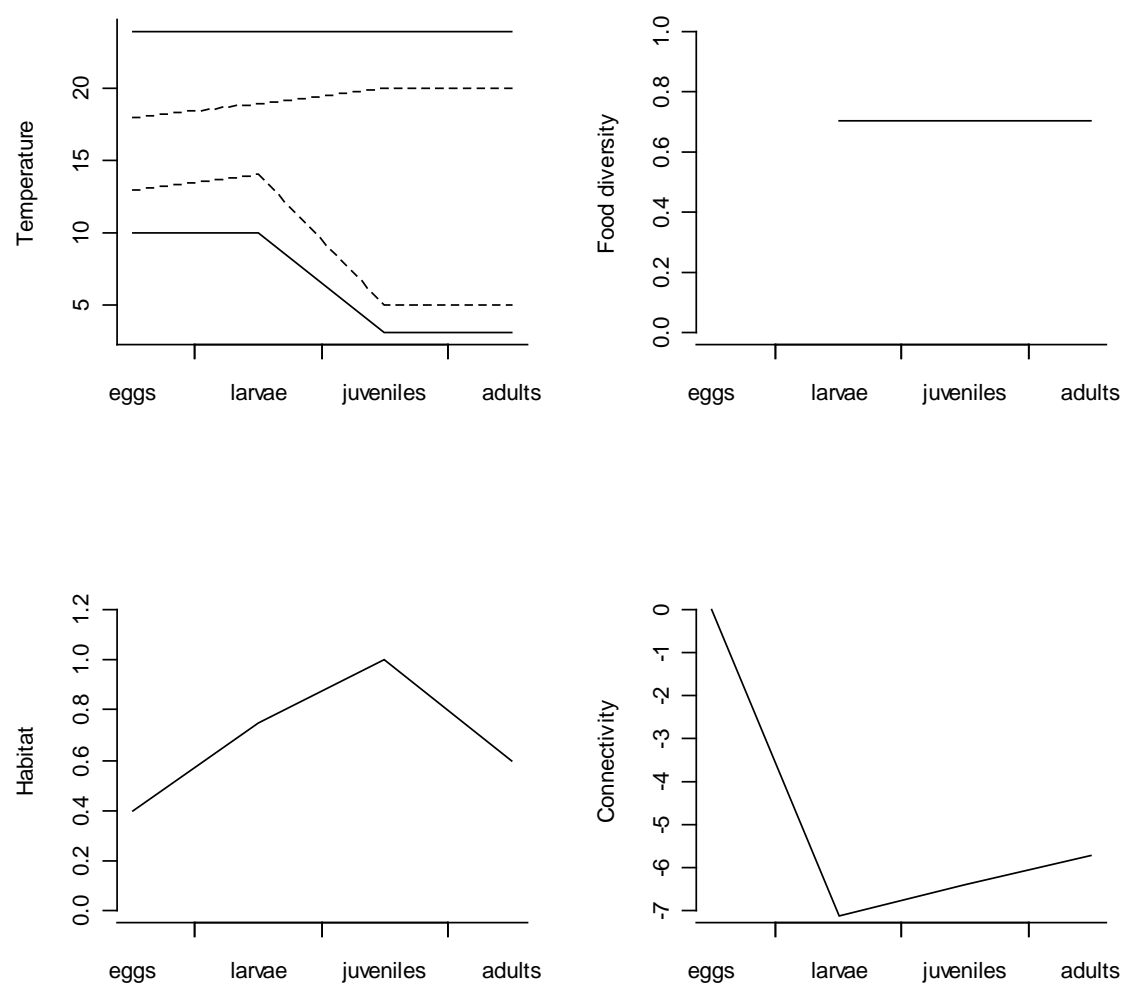

1358

1359 Figure 3 : Bay of Biscay anchovy. Upper left: physiological tolerance range for

1360 temperature (full lines) and the temperature range observed (dashed lines) . Upper right:

1361 food diversity (Shannon index standardized to unity). Lower left: habitat spatial

1362 availability referenced to the largest habitat across the life history stages. Lower right:

1363 connectivity between life history stages expressed as $\log 10(1 /$ distance travelled) where

1364 distance is in body length.

1365 